\title{
Mechanism of Human $\alpha-1,3$-Fucosyltransferase V: Glycosidic Cleavage Occurs Prior to Nucleophilic Attack ${ }^{\dagger}$
}

\author{
Brion W. Murray, Valentin Wittmann, Michael D. Burkart, Shang-Cheng Hung, and Chi-Huey Wong* \\ Department of Chemistry, The Scripps Research Institute, 10550 North Torrey Pines Road, La Jolla, California 92037
}

Received September 10, 1996; Revised Manuscript Received November 13, $1996^{\otimes}$

\begin{abstract}
Fucosyltransferase V (FucT V) catalyzes the transfer of l-fucose from the donor sugar guanosine $5^{\prime}$-diphospho- $\beta$-1-fucose (GDP-Fuc) to an acceptor sugar. A secondary isotope effect on the fucosyltransfer reaction with guanosine $5^{\prime}$-diphospho- $\left[1-{ }^{2} \mathrm{H}\right]-\beta$-1-fucose (GDP-[1- $\left.{ }^{2} \mathrm{H}\right]-\mathrm{Fuc}$ ) as the substrate was observed and determined to be $\mathrm{D}_{V}=1.32 \pm 0.13$ and $\mathrm{D}_{V / K}=1.27 \pm 0.07$. Competitive inhibition of FucT V by guanosine $5^{\prime}$-diphospho-2-deoxy-2-fluoro- $\beta$-1-fucose (GDP-2F-Fuc) was observed with an inhibition constant of $4.2 \mu \mathrm{M}$ which represents the most potent inhibitor of this enzyme to date. Incubation of GDP-2F-Fuc with FucT V and an acceptor molecule prior to the addition of GDP-Fuc had no effect on the potency of inhibition, indicating that GDP-2F-Fuc is neither an inactivator nor a slow substrate. Both the observed secondary isotope effect and the inhibition by GDP-2F-Fuc are consistent with a charged, $\mathrm{sp}^{2}$-hybridized, transition-state structure. A convenient and efficient synthesis of GDP-[1-2 $\left.\mathrm{H}\right]$-Fuc and GDP-2F-Fuc and a nonradioactive, fluorescence assay for fucosyltransferase activity have been developed.
\end{abstract}

The $\alpha-1,3$-fucosylated oligosaccharide structures are central to numerous cell-cell interactions (Ichikawa et al., 1994) such as inflammation, tumor development, and blood clotting (Foxall et al., 1992; Parekh \& Edge, 1994). Five distinct human $\alpha$-1,3-fucosyltransferases have been cloned (KukowskaLatallo et al., 1990; Lowe et al., 1991; McCurley et al., 1995; Reguigne-Arnould et al., 1995; Sasaki et al., 1994; Weston et al., 1992a,b) and shown to have different acceptor sugar specificity. $\alpha-1,3$-Fucosyltransferase $\mathrm{V}$ (FucT V) ${ }^{1}$ is responsible for the terminal step in the biosynthesis of Lewis $\mathrm{x}\left(\operatorname{Le}^{\mathrm{x}}\right)$ and sialyl Lewis $\mathrm{x}\left(\mathrm{sLe}^{\mathrm{x}}\right)$ (Figure 1), a tetrasaccharide ligand involved in inflammatory cell adhesion and metastasis (Lasky, 1992; Muramatsu, 1993). Thus inhibition of this enzyme may impede inflammation or cancer progression, and understanding the mechanism of FucT V may lead to the development of effective inhibitors.

The $\alpha$-1,3-fucosyltransferase $\mathrm{V}$-catalyzed reaction proceeds with inversion of configuration at the anomeric center of l-fucose (Weston et al., 1992a). Product inhibition studies have been used to establish that FucT V has an ordered, sequential, bi-bi mechanism with guanosine 5'-diphospho$\beta$-l-fucose (GDP-Fuc) binding first and the product GDP releasing last (Qiao et al., 1996). FucT V has been shown to have a catalytic residue with $\mathrm{p} K_{\mathrm{a}}=4.1$, presumably an

$\dagger$ This work was partially supported by the NIH (GM 44154), the NSF, Cytel Corporation (San Diego, CA), and the Deutsche Forschungsgemeinschaft (fellowship for V.W.).

* To whom correspondence should be addressed: telephone, 1-619784-2487; Fax, 1-619-784-2409.

${ }^{\otimes}$ Abstract published in Advance ACS Abstracts, January 1, 1997.

${ }^{1}$ Abbreviations: cha, cyclohexylamine; $\mathrm{D}_{V}$, kinetic isotope effect on $V_{\max } ; \mathrm{D}_{V / K}$, kinetic isotope effect on $V_{\max } / K_{\mathrm{m}}$; FucT, fucosyltransferase; FucT V, $\alpha-1,3$-fucosyltransferase V; GDP, guanosine $5^{\prime}$ diphosphate; GDP-[1-2 H]Fuc, guanosine $5^{\prime}$-diphospho- $\left[1-{ }^{2} \mathrm{H}\right]-\beta-1-$ fucose; GDP-2F-Fuc, guanosine $5^{\prime}$-diphospho-2-deoxy-2-fluoro- $\beta$-1fucose; GDP-Fuc, guanosine $5^{\prime}$-diphospho- $\beta$-1-fucose; GMP, guanosine 5 '-monophosphate; GMP-morpholidate, guanosine 5'-monophosphomorpholidate; HRMS, high-resolution mass spectrometry; LacNAc, $N$-acetyllactosamine, Gal $\beta 1,4 \mathrm{GlcNAc}$; Le ${ }^{\mathrm{x}}$, Lewis $\mathrm{x}$; NeuAc, $N$ acetylneuraminic acid; $\mathrm{sLe}^{\mathrm{x}}$, sialyl Lewis $\mathrm{x}$. active-site carboxylate residue (Murray et al., 1996). A solvent isotope effect was observed $\left(\mathrm{D}_{V}=2.9, \mathrm{D}_{V / K}=2.1\right)$ and exploited in a proton inventory study to show that there is a one-proton transfer in the transition state (Murray et al., 1996). The transition-state structure of glycosyltransferasecatalyzed reactions has been proposed to have a flattened half-chair conformation with substantial oxocarbenium ion character at the anomeric position (Kim et al., 1988; Murray et al., 1996), analogous to that of the glycosidase reactions (Look et al., 1993; Sinnott, 1990). Consistent with this proposition is the fact that fluoroglycosides have been used to probe the mechanism of glycosidases (McCarter \& Withers, 1996; Porter et al., 1995; White et al., 1996; Withers et al., 1988; Withers \& Street, 1988). Replacement of the 2- or 5-hydroxyl group of glycosyl analogs with the strong electron-withdrawing group fluorine transforms the parent glycoside into a slow substrate for retaining glycosidases. These compounds have been used as mechanism-based glycosidase inactivators which form a covalent adduct in the enzyme active site. Similarly, it has been shown that $\beta-1,4-$ galactosyltransferase has a secondary isotope effect $\left(\mathrm{D}_{V}=\right.$ $1.21, \mathrm{D}_{V / K}=1.05$ ) (Kim et al., 1988) and that uridine $5^{\prime}$ diphospho-2-deoxy-2-fluoro- $\alpha$-D-galactose is a competitive inhibitor of this enzyme (Hayashi et al., 1996). The proposed transition-state structure of FucT V is also supported by the observation that aza sugars which mimic the charge distribution of the glycosyl cation are inhibitors of FucT V, and synergistic inhibition by the combination of an aza sugar, GDP, and the acceptor sugar to mimic the transition-state structure has been illustrated (Ichikawa et al., 1992a; Murray et al., 1996; Qiao et al., 1996).

With the discovery of many fucosyltransferases, the limiting step in the study of these important enzymes is the synthesis of GDP-Fuc and analogs. Unlike other sugar nucleotides, the enzymatic preparation of GDP-Fuc has not been established on a large scale, and as such, several groups have reported the chemical synthesis of this substrate (Adelhorst \& Whitesides, 1993; Arlt \& Hindsgaul 1995; 


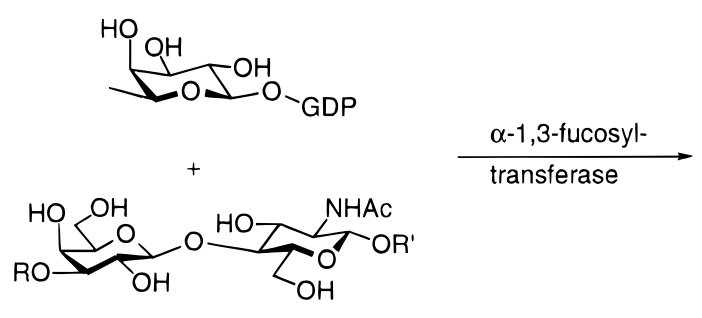

$R=H$ or NeuAc $\alpha-2$

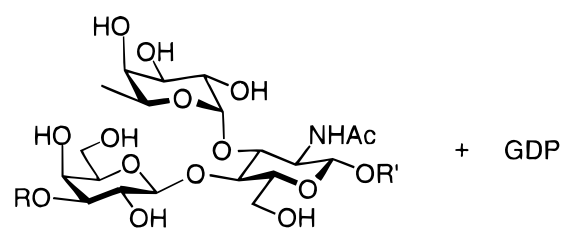

$\mathrm{R}=\mathrm{H}\left(\mathrm{Le}^{\mathrm{x}}\right)$

$R=\operatorname{NeuAc} \alpha-2\left(s L e^{x}\right)$

FIGURE 1: $\alpha-1,3-$ Fucosyltransferase-catalyzed reactions.

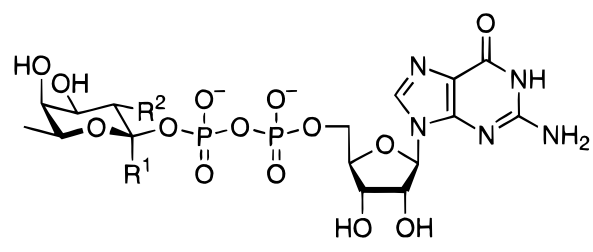

1: $R^{1}=H, R^{2}=O H(G D P-F u c)$

2: $R^{1}=D, R^{2}=O H\left(G D P-\left[1-{ }^{2} H\right]-F u C\right)$

3: $R^{1}=H, R^{2}=F(G D P-2 F-F u c)$

FIGURE 2: Sugar nucleotides used to investigate the transition-state structure of the FucT V reaction.

Gokhale et al., 1990; Ichikawa et al., 1992b; Nunez et al., 1981, Veeneman et al., 1991). A key step in most of these procedures is the coupling of $\beta$-1-fucopyranosyl phosphate with the commercially available guanosine $5^{\prime}$-monophosphomorpholidate (GMP-morpholidate) (Moffatt, 1966; Roseman et al., 1961). While the fucosyl phosphate is obtainable in a high overall yield from 1-fucose ( $82 \%$, five steps) using the published procedures (Adelhorst \& Whitesides, 1993; Ichikawa et al., 1992b), the morpholidate coupling is a slow and low-yielding reaction and therefore not satisfactory.

In this paper, we present an improved procedure for the morpholidate coupling, using $1 H$-tetrazole as a catalyst. GDP-Fuc and the new sugar nucleotides guanosine $5^{\prime}$ diphospho-2-deoxy-2-fluoro- $\beta$-1-fucose (GDP-2F-Fuc) and guanosine $5^{\prime}$-diphospho- $\left[1-{ }^{2} \mathrm{H}\right]-\beta$-1-fucose (GDP-[1-2 $\left.\left.\mathrm{H}\right]-\mathrm{Fuc}\right)$ (Figure 2) are thus obtained in high yields and used to investigate the transition-state structure of the FucT $\mathrm{V}$ reaction. Evidence is presented for $\mathrm{sp}^{2}$ hybridization in the transition state through secondary isotope studies. In addition, the potency of inhibition of GDP-2F-Fuc is presented as evidence of the accumulation of positive charge at the anomeric position of GDP-Fuc in the transition state. A nonradioactive, fluorescence-coupled enzymatic assay for determining FucT V activity is also devised. It is hoped that the methods described here are useful for the study of glycosyltransferases with regard to their mechanism and synthetic application.

\section{MATERIALS AND METHODS}

General Methods. NMR spectra were recorded on Bruker AM-250, AMX-400, or AMX-500 spectrometers. ${ }^{1} \mathrm{H}$ chemical shifts are referenced to residual protic solvent $\left(\mathrm{CDCl}_{3}\right.$, $\left.\delta_{\mathrm{H}}=7.26 ; \mathrm{DMSO}-d_{6}, \delta_{\mathrm{H}}=2.50 ; \mathrm{D}_{2} \mathrm{O}, \delta_{\mathrm{H}}=4.80\right)$ or internal standard TMS $\left(\delta_{\mathrm{H}}=0.00\right)$. ${ }^{13} \mathrm{C}$ NMR spectra are protondecoupled and the multiplicity of the signals is singlet unless otherwise noted. ${ }^{13} \mathrm{C}$ chemical shifts are referenced to the solvent signal $\left(\mathrm{CDCl}_{3}, \delta_{\mathrm{C}}=77.0\right.$; DMSO- $\left.d_{6}, \delta_{\mathrm{C}}=39.5\right)$ or to 1,4 -dioxane $\left(\delta_{\mathrm{C}}=67.6\right.$ in $\left.\mathrm{D}_{2} \mathrm{O}\right)$ as internal standard. ${ }^{19} \mathrm{~F}$ NMR spectra were recorded at $376.5 \mathrm{MHz}$ (Bruker AMX-
400) and referenced to $\mathrm{CFCl}_{3}\left(\delta_{\mathrm{F}}=0.00\right)$ as internal $\left(\mathrm{CDCl}_{3}\right)$ or external $\left(\mathrm{D}_{2} \mathrm{O}\right)$ standard. ${ }^{31} \mathrm{P}$ NMR spectra were recorded at $162.0 \mathrm{MHz}$ (Bruker AMX-400) and referenced to $85 \%$ $\mathrm{H}_{3} \mathrm{PO}_{4}\left(\delta_{\mathrm{P}}=0.00\right)$ as external standard. Coupling constants were measured in hertz. High-resolution mass spectra (HRMS) were recorded using fast atom bombardment (FAB) method in a $m$-nitrobenzyl alcohol matrix doped with $\mathrm{NaI}$ or CsI. Column chromatography was performed on Mallinckrodt silica gel 60 (230-400 mesh). Analytical thin-layer chromatography was performed using silica gel $60 \mathrm{~F}_{254}$ precoated glass plates (Merck) and visualized by quenching of fluorescence and(or) by charring after treatment with cerium molybdophosphate. Size-exclusion chromatography was performed on Bio-Gel P2 gel, fine (Bio-Rad Laboratories). Diethyl ether and benzene were distilled from sodium benzophenone ketyl, dichloromethane and acetonitrile from calcium hydride. Anhydrous pyridine was purchased from Aldrich and used without further purification. $N$-Acetyllactosamine, Dowex 1-X8, MES, pyruvate kinase, lactate dehydrogenase, PEP, GDP, NADH, guanosine 5'-monophosphomorpholidate 4-morpholine- $N, N^{\prime}$-dicyclohexylcarboxamidine salt, and cacodylic acid were purchased from Sigma. Guanosine $5^{\prime}$-diphospho-[U-14C]- $\beta$-l-fucose was purchased from Amersham Life Science. ScintiVerseI scintillation cocktail and $\mathrm{MnCl}_{2} \cdot 4 \mathrm{H}_{2} \mathrm{O}$ were purchased from Fisher Scientific Co. Protein concentrations were determined with the Coomassie protein staining reagent with albumin standards as purchased from Pierce. The scintillation counter used was the Beckman LS 3801. Fluorescence was measured on a Hitachi F2000 fluorescence spectrophotometer. Human $\alpha$-1,3-fucosyltransferase and LacNAc- $\beta$-O- $\left(\mathrm{CH}_{2}\right)_{5} \mathrm{CO}_{2} \mathrm{CH}_{3}$ were prepared according to published procedures (Murray et al., 1996).

Synthesis of GDP-[1-2H]-Fuc (2) (Scheme 1): (A) 1,2,3,4Tetra-O-benzoyl-[1-2H]-l-fucopyranoside (5). 1-Fuconic acid 4, prepared from 1-fucose by catalytic dehydrogenation (de Wit et al., 1978) (500 mg, $2.78 \mathrm{mmol}$ ) was dissolved in $1 \mathrm{~N}$ $\mathrm{HCl}(1.75 \mathrm{~mL})$ and the solution was stirred at room temperature for $5 \mathrm{~h}$. Into the mixture was added $1 \mathrm{~N} \mathrm{NaOH}$ (ca. $1.7 \mathrm{~mL}$ ) to reach a $\mathrm{pH}$ of $4-5$, and a solution of $\mathrm{NaBD}_{4}$ $(0.25 \mathrm{~g}, 5.97 \mathrm{mmol})$ in $\mathrm{H}_{2} \mathrm{O}(0.8 \mathrm{~mL})$ was added dropwise over $1 \mathrm{~h}$. During the addition, a diluted $\mathrm{HCl}$ solution was added to maintain the $\mathrm{pH}$ value at $4-5$. The mixture was quenched with $1 \mathrm{~N} \mathrm{HCl}(2 \mathrm{~mL})$, and the resulting solution was coevaporated four times with methanol and dried under high vacuum. To a solution of the crude $\left[1-{ }^{2} \mathrm{H}\right]-1$-fucose in anhydrous pyridine $(16 \mathrm{~mL})$ was added benzoyl chloride $(3$ $\mathrm{mL}$ ) at $0{ }^{\circ} \mathrm{C}$ under argon, and the mixture was stirred overnight at room temperature. The resulting solution was diluted with water $(15 \mathrm{~mL})$, and the aqueous layer was extracted with EtOAc $(3 \times 15 \mathrm{~mL})$. The combined organic 
layers were washed with $4 \mathrm{~N} \mathrm{HCl}, 1 \mathrm{~N} \mathrm{HCl}, \mathrm{H}_{2} \mathrm{O}$, saturated $\mathrm{NaHCO}_{3}$ and brine, dried with $\mathrm{MgSO}_{4}$, filtered, evaporated, and purified by column chromatography on silica gel $(4: 1$ hexane-EtOAc) to yield 5 (375 $\mathrm{mg}, 23 \%)$ as a light yellow syrup $\left(R_{f} 0.43,2: 1\right.$ hexane-EtOAc). ${ }^{1} \mathrm{H} \mathrm{NMR}\left(\mathrm{CDCl}_{3}, 400\right.$ $\mathrm{MHz}) \delta 1.32\left(\mathrm{~d}, J_{6,5}=6.5,3 \mathrm{H}, \mathrm{H}-6\right), 4.64\left(\mathrm{dq}, J_{5,4}=1.2\right.$, and $\left.J_{5,6}=6.5,1 \mathrm{H}, \mathrm{H}-5\right), 5.90\left(\mathrm{dd}, J_{4,5}=1.2\right.$, and $J_{4,3}=$ $3.3,1 \mathrm{H}, \mathrm{H}-4), 5.99\left(\mathrm{~d}, J_{2,3}=10.7,1 \mathrm{H}, \mathrm{H}-2\right), 6.08\left(\mathrm{dd}, J_{3,4}\right.$ $=3.3$, and $\left.J_{3,2}=10.7,1 \mathrm{H}, \mathrm{H}-3\right)$, and $7.22-8.18(\mathrm{~m}, 20 \mathrm{H}$, $\left.4 \mathrm{C}_{6} \mathrm{H}_{5}\right) ;{ }^{13} \mathrm{C} \mathrm{NMR}\left(\mathrm{CDCl}_{3}, 100 \mathrm{MHz}\right) \delta 16.20,67.49,67.86$, 68.91, 71.34, 90.78, 128.26, 128.31, 128.44, 128.52, 128.66, $128.70,129.62,129.69,129.88,129.92,129.98,133.30$, 133.37, 133.58, 133.77, 164.68, 165.59, 165.78, and 165.90; HRMS calcd for $\mathrm{C}_{34} \mathrm{H}_{27} \mathrm{CsDO}_{9}\left(\mathrm{M}+\mathrm{Cs}^{+}\right) 714.0850$, found 714.0882 .

(B) 2,3,4-Tri-O-benzoyl-[1-2 H]- $\beta$-l-fucopyranosyl Dibenzyl Phosphate (6). To a cooled solution of 5 (141 mg, 0.24 mmol) in $\mathrm{CH}_{2} \mathrm{Cl}_{2}(1.1 \mathrm{~mL})$ and $\mathrm{Ac}_{2} \mathrm{O}(0.12 \mathrm{~mL})$ was added dropwise a $30 \%$ solution of $\mathrm{HBr}$ in $\mathrm{HOAc}(0.5 \mathrm{~mL})$ at $0{ }^{\circ} \mathrm{C}$. The mixture was stirred for $2 \mathrm{~h}$ at $0{ }^{\circ} \mathrm{C}$ and then poured onto ice water. The aqueous layer was extracted with $\mathrm{CH}_{2} \mathrm{Cl}_{2}$ $(3 \times 5 \mathrm{~mL})$ and the combined organic layers were washed with water, saturated $\mathrm{NaHCO}_{3}$, and brine, dried with $\mathrm{MgSO}_{4}$, filtered, and evaporated. To a solution of the crude glycosyl bromide in $\mathrm{CH}_{2} \mathrm{Cl}_{2}-\mathrm{Et}_{2} \mathrm{O}-\mathrm{CH}_{3} \mathrm{CN}$ (1.4 mL each) was added 4- $\AA$ molecular sieves $(0.38 \mathrm{~g})$ at room temperature under argon. The mixture was stirred for $2 \mathrm{~h}$ and $\mathrm{HOPO}(\mathrm{OBn})_{2}$ (66.7 mg, $0.24 \mathrm{mmol}$ ) and $\mathrm{Ag}_{2} \mathrm{CO}_{3}(0.13 \mathrm{~g}, 0.47 \mathrm{mmol})$ were added in one portion. The mixture was stirred for $16 \mathrm{~h}$ in the dark, filtered through Celite, evaporated, and purified by column chromatography on silica gel (2:1 hexane-EtOAc with $\left.5 \% \mathrm{Et}_{3} \mathrm{~N}\right)$ to yield $6(144 \mathrm{mg}, 80 \%)$ as a white foam $\left(R_{f} 0.41,1: 1\right.$ hexane-EtOAc). The degree of deuteration at C-1 was ${ }^{1} \mathrm{H}$ NMR spectroscopically determined to be $89 \%$. ${ }^{1} \mathrm{H} \mathrm{NMR}\left(\mathrm{CDCl}_{3}, 400 \mathrm{MHz}\right) \delta 1.35\left(\mathrm{~d}, J_{6,5}=6.3,3 \mathrm{H}, \mathrm{H}-6\right)$, 4.21 (br q, $\left.J_{5,6}=6.3,1 \mathrm{H}, \mathrm{H}-5\right), 4.77\left(\mathrm{dd}, J_{\mathrm{H}, \mathrm{P}}=7.1\right.$ and $J_{\mathrm{H}, \mathrm{H}}=11.7,1 \mathrm{H}$, benzylic), $4.87\left(\mathrm{dd}, J_{\mathrm{H}, \mathrm{P}}=6.5\right.$ and $J_{\mathrm{H}, \mathrm{H}}=$ $11.7,1 \mathrm{H}$, benzylic), $5.10\left(\mathrm{dd}, J_{\mathrm{H}, \mathrm{P}}=7.5\right.$ and $J_{\mathrm{H}, \mathrm{H}}=11.7$, $1 \mathrm{H}$, benzylic), $5.15\left(\mathrm{dd}, J_{\mathrm{H}, \mathrm{P}}=7.3\right.$ and $J_{\mathrm{H}, \mathrm{H}}=11.7,1 \mathrm{H}$, benzylic), 5.59 (dd, $J_{3,4}=3.3$ and $J_{3,2}=10.4,1 \mathrm{H}, \mathrm{H}-3$ ), 5.77 (br d, $\left.J_{4,3}=3.3,1 \mathrm{H}, \mathrm{H}-4\right), 5.91\left(\mathrm{~d}, J_{2,3}=10.4,1 \mathrm{H}\right.$, $\mathrm{H}-2)$, and $7.00-8.12\left(\mathrm{~m}, 25 \mathrm{H}, 5 \mathrm{C}_{6} \mathrm{H}_{5}\right) ;{ }^{13} \mathrm{C} \mathrm{NMR}(100$ $\left.\mathrm{MHz} \mathrm{CDCl}_{3}\right) \delta 16.09(\mathrm{C}-6), 69.26\left(\mathrm{~d}, J_{\mathrm{C}, \mathrm{P}}=5.6\right), 69.49(\mathrm{~d}$, $\left.J_{\mathrm{C}, \mathrm{P}}=4.9\right), 69.60,70.52,70.76,71.66,96.92\left(\mathrm{~d}, J_{\mathrm{C}, \mathrm{P}}=4.8\right)$, $127.29,127.81,128.23,128.27,128.55,128.61,128.78$, $129.01,129.60,129.67,129.89,133.24,133.39,133.49$, 134.94, 135.02, 135.38, 135.46, 165.21, 165.41, and 165.75; HRMS calcd for $\mathrm{C}_{41} \mathrm{H}_{36} \mathrm{CsDO}_{11} \mathrm{P}\left(\mathrm{M}+\mathrm{Cs}^{+}\right) 870.1191$, found 870.1228 .

(C) Di(cyclohexylammonium) $\left[1-{ }^{2} H\right]-\beta-l-F u c o p y r a n o s y l$ Phosphate (7). A solution of $6(110 \mathrm{mg}, 0.15 \mathrm{mmol})$ in toluene $(2 \mathrm{~mL})$, pyridine $(0.18 \mathrm{~mL})$, and triethylamine $(0.14$ $\mathrm{mL}$ ) was stirred overnight under a hydrogen atmosphere with $10 \%$ palladium on carbon $(10 \mathrm{mg})$ as catalyst. The mixture was filtered through Celite and the filtrate was concentrated to yield bis(triethylammonium) $2,3,4$-tri- $O$-benzoyl- $\left[1-{ }^{2} \mathrm{H}\right]$ $\beta$-l-fucopyranosyl phosphate as a dry foam (108 $\mathrm{mg}, 95 \%)$. ${ }^{1} \mathrm{H} \mathrm{NMR}\left(\mathrm{CDCl}_{3}, 250 \mathrm{MHz}\right) \delta 1.22\left(\mathrm{~m}, 18 \mathrm{H}, 6 \mathrm{CH}_{2} \mathrm{CH}_{3}\right)$, $1.24\left(\mathrm{~d}, J_{6,5}=6.4,3 \mathrm{H}, \mathrm{H}-6\right), 2.97\left(\mathrm{~m}, 12 \mathrm{H}, 6 \mathrm{CH}_{2} \mathrm{CH}_{3}\right)$, 4.18 (br q, $\left.J_{5,6}=6.4,1 \mathrm{H}, \mathrm{H}-5\right), 5.60\left(\mathrm{dd}, J_{3,4}=3.2\right.$, and $J_{3,2}=10.4,1 \mathrm{H}, \mathrm{H}-3$ ), 5.69 (br d, $\left.J_{4,3}=3.2,1 \mathrm{H}, \mathrm{H}-4\right), 5.75$ $\left(\mathrm{d}, J_{2,3}=10.4,1 \mathrm{H}, \mathrm{H}-2\right)$, and 7.12-8.14 (m, $\left.15 \mathrm{H}, 3 \mathrm{C}_{6} \mathrm{H}_{5}\right)$.
To a solution of the debenzylated phosphate (108 mg, 0.14 $\mathrm{mmol})$ in $\mathrm{MeOH}(0.7 \mathrm{~mL})$ was added cyclohexylamine $(0.7$ $\mathrm{mL})$ at room temperature under argon. The mixture was refluxed for $4 \mathrm{~h}$ and the reaction was monitored by TLC in 7:2:1 $i$-PrOH $-\mathrm{H}_{2} \mathrm{O}-\mathrm{NH}_{4} \mathrm{OH}$. When debenzoylation was achieved, the mixture was concentrated and fractionated between water and $\mathrm{CHCl}_{3}$. The water phase was washed with $\mathrm{CHCl}_{3}$ three times and then concentrated to dryness by coevaporating $\mathrm{MeOH}$. The product was dissolved in hot EtOH and precipitated by addition of acetone. The product was separated by filtration to yield 7 as a white solid (52.2 $\mathrm{mg}, 83 \%) .{ }^{1} \mathrm{H} \mathrm{NMR}\left(400 \mathrm{MHz}, \mathrm{D}_{2} \mathrm{O}, \mathrm{pH} 7.0\right) \delta 1.06(\mathrm{~m}, 2$ $\mathrm{H}$, cha), 1.15 (d, $\left.J_{6,5}=6.3,3 \mathrm{H}, \mathrm{H}-6\right), 1.24$ (m, $8 \mathrm{H}$, cha), 1.54 (m, $2 \mathrm{H}$, cha), 1.69 (m, $4 \mathrm{H}$, cha), 1.87 (m, $4 \mathrm{H}$, cha), 3.03 (m, $2 \mathrm{H}$, cha), 3.40 (d, $\left.J_{2,3}=9.9,1 \mathrm{H}, \mathrm{H}-2\right), 3.57$ (dd, $J_{3,4}=2.8$ and $\left.J_{3,2}=9.9,1 \mathrm{H}, \mathrm{H}-3\right), 3.62\left(\right.$ br d $J_{4,3}=2.8,1$ $\mathrm{H}, \mathrm{H}-4$ ), and 3.70 (br q, $J_{5,6}=6.3,1 \mathrm{H}, \mathrm{H}-5$ ); ${ }^{13} \mathrm{C} \mathrm{NMR}$ (100 MHz, $\left.\mathrm{D}_{2} \mathrm{O}, \mathrm{pH} 7.0\right) \delta 17.96,26.20,26.72,32.83,52.63$, 73.46, 73.66, 74.29, 75.19, and $99.96\left(\mathrm{~d}, J_{\mathrm{C}, \mathrm{P}}=5.1\right)$.

(D) Guanosine 5'-Diphospho- $\left[1-{ }^{2} H\right]-\beta$-l-fucose, Monoammonium Salt (2). Compound 7 (52.2 mg, $0.118 \mathrm{mmol})$ was dissolved in water $(1 \mathrm{~mL})$, applied to a Bio-Rad AG $50 \mathrm{~W}-\mathrm{X} 2$ cation-exchange column $\left(\mathrm{Et}_{3} \mathrm{~N}^{+}\right.$form; $\left.0.8 \times 8 \mathrm{~cm}\right)$, and eluted with water $(15 \mathrm{~mL})$. The combined fractions were concentrated, and the residual solvent was coevaporated three times with anhydrous pyridine, keeping the flask moisturefree by using argon to bring the pressure back to normal. The crude compound was added guanosine $5^{\prime}$-monophosphomorpholidate 4-morpholine- $N, N^{\prime}$-dicyclohexylcarboxamidine salt $(180 \mathrm{mg}, 0.189 \mathrm{mmol})$ and the mixture was coevaporated with dry pyridine three times. To the mixture was added $1 H$-tetrazole $(30 \mathrm{mg})$ and anhydrous pyridine $(0.73 \mathrm{~mL})$, and the solution was stirred at room temperature for 2 days. The resulting solution was concentrated, dissolved in a small amount of water, and applied to a Bio-Gel P2 column $(2.5 \times 65 \mathrm{~cm})$ using $250 \mathrm{mM} \mathrm{NH}_{4} \mathrm{HCO}_{3}$ as eluent to yield $2(56.2 \mathrm{mg}, 78 \%)$ as a white solid $\left(R_{f} 0.43,2: 1\right.$ $i$-PrOH-1 $\left.\mathrm{M} \mathrm{NH}_{4} \mathrm{OAc}\right)$. The degree of deuteration at C-1 of fucose was determined by ${ }^{1} \mathrm{H}$ NMR spectroscopy and mass spectrometry. Within the experimental error a common value of $86 \%$ was obtained. ${ }^{1} \mathrm{H}$ NMR $\left(\mathrm{D}_{2} \mathrm{O}, 500 \mathrm{MHz}\right) \delta 1.19(\mathrm{~d}$, $J_{6,5}=6.5,3$ H, H-6 Fuc), 3.52 (d, $J_{2,3}=9.9,1$ H, H-2 Fuc), $3.62\left(\mathrm{dd}, J_{3,4}=3.5\right.$ and $\left.J_{3,2}=9.9,1 \mathrm{H}, \mathrm{H}-3 \mathrm{Fuc}\right), 3.67(\mathrm{dd}$, $J_{4,5}=0.9$ and $J_{4,3}=3.5,1 \mathrm{H}, \mathrm{H}-4$ Fuc), $3.73\left(\mathrm{dq}, J_{5,4}=0.9\right.$ and $J_{5,6}=6.5,1 \mathrm{H}, \mathrm{H}-5$, Fuc), 4.17 (m, $2 \mathrm{H}, \mathrm{H}-5 \mathrm{Rib}$ ), 4.31 (m, 1 H, H-4 Rib), $4.50\left(\mathrm{dd}, J_{3,4}=3.1\right.$ and $J_{3,2}=5.2,1 \mathrm{H}$, H-3 Rib), 4.78 (dd, $J_{2,3}=5.2$ and $J_{2,1}=6.3,1 \mathrm{H}, \mathrm{H}-2 \mathrm{Rib}$ ), $5.89\left(\mathrm{~d}, J_{1,2}=6.3,1 \mathrm{H}, \mathrm{H}-1 \mathrm{Rib}\right)$, and $8.07(\mathrm{~s}, 1 \mathrm{H}, \mathrm{H}-8$ base).

Synthesis of GDP-2F-Fuc (3) (Scheme 2): (A) 2-Deoxy2-fluoro-l-fucose. 2-Deoxy-2-fluoro-3,4-di- $O$-acetyl- $\alpha$-1fucopyranosyl fluoride 8, prepared from 3,4-di- $O$-acetyl-1fucal using xenon difluoride (Korytnyk, 1982) (2.4 g, 14.5 mmol), was hydrolyzed in $2 \mathrm{~N} \mathrm{HCl}$ solution $(15 \mathrm{~mL})$ at 90 ${ }^{\circ} \mathrm{C}$ for $1 \mathrm{~h}$. The solution was slowly cooled to $0{ }^{\circ} \mathrm{C}$, neutralized with $\mathrm{K}_{2} \mathrm{CO}_{3}$, and evaporated to dryness. The residue was dissolved in $\mathrm{MeOH}(30 \mathrm{~mL})$ and filtered to remove salts. After evaporation, the residue was purified by silica gel chromatography $\left(25: 2 \mathrm{CH}_{2} \mathrm{Cl}_{2}-\mathrm{MeOH}\right)$ to afford the title compound $(1.80 \mathrm{~g}, 75 \%)$ as a white solid $\left(R_{f}\right.$ 0.61, 25:2 $\left.\mathrm{CH}_{2} \mathrm{Cl}_{2}-\mathrm{MeOH}\right)$. ${ }^{1} \mathrm{H} \mathrm{NMR}$ analysis of the product indicated a mixture of $\alpha$ and $\beta$ anomers in a ratio of 1:1.7. ${ }^{1} \mathrm{H}$ NMR $\left(\mathrm{D}_{2} \mathrm{O}, 500 \mathrm{MHz}\right), \alpha$ anomer, $\delta 1.16(\mathrm{~d}$, 
$\left.J_{6,5}=6.6,3 \mathrm{H}, \mathrm{H}-6\right), 3.83\left(\mathrm{ddd}, J_{4,5}=1.4\right.$ and $J_{4,3} \approx J_{4, \mathrm{~F}} \approx$ $3.7,1 \mathrm{H}, \mathrm{H}-4), 4.07$ (ddd, $J_{3,4}=3.6, J_{3,2}=10.1$, and $J_{3, \mathrm{~F}}=$ 12.6, $1 \mathrm{H}, \mathrm{H}-3), 4.19\left(\mathrm{dq}, J_{5,4}=1.4\right.$ and $J_{5,6}=6.6,1 \mathrm{H}$, H-5), 4.58 (ddd, $J_{2,1}=4.0, J_{2,3}=10.1$, and $J_{2, \mathrm{~F}}=49.8,1$ $\mathrm{H}, \mathrm{H}-2)$, and $5.36\left(\mathrm{~d}, J_{1,2}=4.0,1 \mathrm{H}, \mathrm{H}-1\right) ; \beta$ anomer, $\delta$ $1.20\left(\mathrm{~d}, J_{6,5}=6.5,3 \mathrm{H}, \mathrm{H}-6\right), 3.77\left(\mathrm{ddd}, J_{4,5}=1.2\right.$ and $J_{4,3}$ $\left.\approx J_{4, \mathrm{~F}} \approx 3.4,1 \mathrm{H}, \mathrm{H}-4\right), 3.80\left(\mathrm{dq}, J_{5,4}=1.2\right.$ and $J_{5,6}=6.5$, $1 \mathrm{H}, \mathrm{H}-5$ ), 3.89 (ddd, $J_{3,4}=3.6, J_{3,2}=9.5$, and $J_{3, \mathrm{~F}}=14.4$, $1 \mathrm{H}, \mathrm{H}-3$ ), 4.25 (ddd, $J_{2,1}=7.8, J_{2,3}=9.6$, and $J_{2, \mathrm{~F}}=52.1$, $1 \mathrm{H}, \mathrm{H}-2), 4.76\left(\mathrm{dd}, J_{1, \mathrm{~F}}=3.4\right.$ and $\left.J_{1,2}=7.8,1 \mathrm{H}, \mathrm{H}-1\right) ;{ }^{13} \mathrm{C}$ NMR $\left(\mathrm{D}_{2} \mathrm{O}, 120 \mathrm{MHz}\right), \alpha$ anomer, $\delta 17.75(\mathrm{C}-6), 70.20(\mathrm{~d}$, $\left.J_{3, \mathrm{~F}}=17.2, \mathrm{C}-3\right), 73.58(\mathrm{C}-5), 74.81\left(\mathrm{~d}, J_{4, \mathrm{~F}}=8.7, \mathrm{C}-4\right)$, $91.34\left(\mathrm{~d}, J_{2, \mathrm{~F}}=182.0, \mathrm{C}-2\right)$, and $92.22\left(\mathrm{~d}, J_{1, \mathrm{~F}}=21.4, \mathrm{C}-1\right)$; $\beta$ anomer, $\delta 17.75$ (C-6), $68.80(\mathrm{C}-5), 73.79\left(\mathrm{~d}, J_{3, \mathrm{~F}}=16.7\right.$, C-3), 74.41 (d, $\left.J_{4, \mathrm{~F}}=8.9, \mathrm{C}-4\right), 94.85\left(\mathrm{~d}, J_{2, \mathrm{~F}}=179.4, \mathrm{C}-2\right)$, and $96.21\left(\mathrm{~d}, J_{1, \mathrm{~F}}=23.5, \mathrm{C}-1\right)$; HRMS calcd for $\mathrm{C}_{6} \mathrm{H}_{11} \mathrm{FNaO}_{4}$ $\left(\mathrm{M}+\mathrm{Na}^{+}\right)$189.0539, found 189.0534.

(B) 1,3,4-Tri-O-acetyl-2-deoxy-2-fluoro-l-fucopyranose (9). A mixture of 2-deoxy-2-fluoro-1-fucose $(1.0 \mathrm{~g}, 6.0 \mathrm{mmol})$ and $\mathrm{Ac}_{2} \mathrm{O}(3.4 \mathrm{~mL}, 36 \mathrm{mmol})$ in pyridine $(5 \mathrm{~mL})$ was stirred overnight at room temperature. The mixture was concentrated to an oil, which was coevaporated three times with toluene. The residue was purified by silica gel chromatography (2:1 hexane-EtOAc) to give $9(1.26 \mathrm{~g}, 72 \%)$ as a colorless syrup $\left(R_{f} 0.32,2: 1\right.$ hexane-EtOAc). ${ }^{1} \mathrm{H}$ NMR analysis showed an $\alpha / \beta$ ratio of 1.5:1. ${ }^{1} \mathrm{H} \mathrm{NMR}\left(\mathrm{CDCl}_{3}\right.$, $500 \mathrm{MHz}), \alpha$ anomer, $\delta 1.08\left(\mathrm{~d}, J_{6,5}=6.5,3 \mathrm{H}, \mathrm{H}-6\right), 1.99$ (s, $\left.3 \mathrm{H}, \mathrm{C}(\mathrm{O}) \mathrm{CH}_{3}\right), 2.10\left(\mathrm{~s}, 6 \mathrm{H}, 2 \mathrm{C}(\mathrm{O}) \mathrm{CH}_{3}\right), 4.19$ (br q, $\left.J_{5,6}=6.5,1 \mathrm{H}, \mathrm{H}-5\right), 4.82\left(\mathrm{ddd}, J_{2,1}=4.0, J_{2,3}=10.2\right.$, and $\left.J_{2, \mathrm{~F}}=49.4,1 \mathrm{H}, \mathrm{H}-2\right), 5.29\left(\mathrm{br} \mathrm{dd}, J_{4,3}=3.4\right.$ and $J_{4, \mathrm{~F}}=3.4$, $1 \mathrm{H}, \mathrm{H}-4), 5.34$ (ddd, $J_{3,4}=3.4, J_{3,2}=10.2$, and $J_{3, \mathrm{~F}}=11.1$, $1 \mathrm{H}, \mathrm{H}-3)$, and $6.35\left(\mathrm{~d}, J_{1,2}=3.9,1 \mathrm{H}, \mathrm{H}-1\right) ; \beta$ anomer, $\delta$ $1.15\left(\mathrm{~d}, J_{6,5}=6.4,3 \mathrm{H}, \mathrm{H}-6\right), 1.99\left(\mathrm{~s}, 3 \mathrm{H}, \mathrm{C}(\mathrm{O}) \mathrm{CH}_{3}\right), 2.10$ (s, $\left.3 \mathrm{H}, \mathrm{C}(\mathrm{O}) \mathrm{CH}_{3}\right), 2.11$ (s, $\left.3 \mathrm{H}, \mathrm{C}(\mathrm{O}) \mathrm{CH}_{3}\right), 3.95$ (br q, $J=$ $6.4,1 \mathrm{H}, \mathrm{H}-5), 4.56\left(\mathrm{ddd}, J_{2,1}=8.0, J_{2,3}=9.8\right.$, and $J_{2, \mathrm{~F}}=$ $51.9,1 \mathrm{H}, \mathrm{H}-2), 5.13\left(\mathrm{ddd}, J_{3,4}=3.6, J_{3,2}=9.8\right.$, and $J_{3, \mathrm{~F}}=$ 13.1, $1 \mathrm{H}, \mathrm{H}-3), 5.23(\mathrm{~m}, 1 \mathrm{H}, \mathrm{H}-4)$, and $5.73\left(\mathrm{dd}, J_{1, \mathrm{~F}}=4.1\right.$ and $\left.J_{1,2}=8.0,1 \mathrm{H}, \mathrm{H}-1\right) ;{ }^{13} \mathrm{C} \mathrm{NMR}\left(\mathrm{CDCl}_{3}, 125 \mathrm{MHz}\right), \alpha$ anomer, $\delta 15.5(\mathrm{C}-6), 20.3,20.4,20.7\left(3 \mathrm{C}(\mathrm{O}) \mathrm{CH}_{3}\right), 66.9$ $(\mathrm{C}-5), 68.4\left(\mathrm{~d}, J_{3, \mathrm{~F}}=18.6, \mathrm{C}-3\right), 70.8\left(\mathrm{~d}, J_{4, \mathrm{~F}}=7.8, \mathrm{C}-4\right)$, $84.0\left(\mathrm{~d}, J_{2, \mathrm{~F}}=190.5, \mathrm{C}-2\right), 89.0\left(\mathrm{~d}, J_{1, \mathrm{~F}}=22.2, \mathrm{C}-1\right), 168.9$, 169.9, and $170.1(3 \mathrm{C}=\mathrm{O}) ; \beta$ anomer, $\delta 15.5(\mathrm{C}-6), 20.3$, 20.4, $20.6\left(3 \mathrm{C}(\mathrm{O}) \mathrm{CH}_{3}\right), 70.0(\mathrm{C}-5), 70.4\left(\mathrm{~d}, J_{4, \mathrm{~F}}=8.2, \mathrm{C}-4\right)$, $71.1\left(\mathrm{~d}, J_{3, \mathrm{~F}}=18.4, \mathrm{C}-3\right), 86.7\left(\mathrm{~d}, J_{2, \mathrm{~F}}=187.7, \mathrm{C}-2\right), 91.4$ $\left(\mathrm{d} J_{1, \mathrm{~F}}=24.1, \mathrm{C}-1\right), 168.8,169.6$, and $170.1(3 \mathrm{C}=\mathrm{O})$; HRMS calcd for $\mathrm{C}_{12} \mathrm{H}_{17} \mathrm{FNaO}_{7}\left(\mathrm{M}+\mathrm{Na}^{+}\right) 315.0856$, found 315.0861 .

(C) 3,4-Di-O-acetyl-2-deoxy-2-fluoro- $\alpha$-l-fucopyranosyl Bromide. A $30 \%$ solution of $\mathrm{HBr}$ in HOAc $(10 \mathrm{~mL})$ was added dropwise into a solution of 9 (1.22 $\mathrm{g}, 4.17 \mathrm{mmol})$ in $\mathrm{CH}_{2} \mathrm{Cl}_{2}(25 \mathrm{~mL})$ and $\mathrm{Ac}_{2} \mathrm{O}(2.5 \mathrm{~mL})$ at $0{ }^{\circ} \mathrm{C}$. The solution was stirred for $2 \mathrm{~h}$ at $0{ }^{\circ} \mathrm{C}$, warmed to room temperature, and stirred an additional $1 \mathrm{~h}$. The reaction mixture was poured on ice-cold water and extracted with $\mathrm{CH}_{2} \mathrm{Cl}_{2}(2 \times$ $50 \mathrm{~mL}$ ). The combined extracts were washed with saturated $\mathrm{Na}_{2} \mathrm{CO}_{3}(2 \times 100 \mathrm{~mL})$ and brine. The organic layer was dried $\left(\mathrm{MgSO}_{4}\right)$ and evaporated to yield the title compound $(1.29 \mathrm{~g}, 99 \%)$ as a light yellow syrup used in the subsequent step without purification $\left(R_{f} 0.47,2: 1\right.$ hexane-EtOAc). ${ }^{1} \mathrm{H}$ NMR analysis indicated the $\alpha$ anomer exclusively. ${ }^{1} \mathrm{H}$ NMR $\left(\mathrm{CDCl}_{3}, 500 \mathrm{MHz}\right) \delta 1.22\left(\mathrm{~d}, J_{6,5}=6.5,3 \mathrm{H}, \mathrm{H}-6\right), 2.06(\mathrm{~s}$, $\left.3 \mathrm{H}, \mathrm{C}(\mathrm{O}) \mathrm{CH}_{3}\right), 2.17$ (s, $\left.3 \mathrm{H}, \mathrm{C}(\mathrm{O}) \mathrm{CH}_{3}\right), 4.44$ (br q, $J_{5,6}=$ $6.5,1 \mathrm{H}, \mathrm{H}-5), 4.74\left(\mathrm{ddd}, J_{2,1}=4.2, J_{2,3}=10.0\right.$, and $J_{2, \mathrm{~F}}=$
50.4, $1 \mathrm{H}, \mathrm{H}-2$ ), 5.38 (br dd, $J_{4,3} \approx J_{4, \mathrm{~F}} \approx 3.4,1 \mathrm{H}, \mathrm{H}-4$ ), $5.48\left(\mathrm{ddd}, J_{3,4}=3.4, J_{3,2}=10.0\right.$, and $\left.J_{3, \mathrm{~F}}=10.1,1 \mathrm{H}, \mathrm{H}-3\right)$, and $6.60\left(\mathrm{~d}, J_{1,2}=4.2,1 \mathrm{H}, \mathrm{H}-1\right) ;{ }^{13} \mathrm{C} \mathrm{NMR}\left(\mathrm{CDCl}_{3}, 125\right.$ $\mathrm{MHz}) \delta 15.4(\mathrm{C}-6), 20.5,20.6\left(2 \mathrm{C}(\mathrm{O}) \mathrm{CH}_{3}\right), 69.4\left(\mathrm{~d}, J_{3, \mathrm{~F}}=\right.$ 17.6, C-3), 70.0 (C-5), 70.5 (d, $\left.J_{4, \mathrm{~F}}=7.3, \mathrm{C}-4\right), 84.3$ (d, $J_{2, \mathrm{~F}}$ $=194.5, \mathrm{C}-2), 87.9\left(\mathrm{~d}, J_{1, \mathrm{~F}}=25.0, \mathrm{C}-1\right)$, and 169.8, 170.1 $(2 \mathrm{C}=\mathrm{O})$; HRMS calcd for $\mathrm{C}_{10} \mathrm{H}_{14} \mathrm{FNaO}_{5}\left(\mathrm{M}-\mathrm{Br}+\mathrm{Na}^{+}\right)$ 255.0645 , found 255.0640 .

(D) (3,4-Di-O-acetyl-2-deoxy-2-fluoro- $\beta$-l-fucopyranosyl) Dibenzyl Phosphate (10). 3,4-Di-O-acetyl-2-deoxy-2-fluoro$\alpha$-l-fucopyranosyl bromide (500 $\mathrm{mg}, 1.60 \mathrm{mmol}$ ), having been coevaporated twice with benzene, was dissolved in $\mathrm{CH}_{2} \mathrm{Cl}_{2}-\mathrm{Et}_{2} \mathrm{O}-\mathrm{CH}_{3} \mathrm{CN}$ (9.5 mL each) and stirred with $4-\AA$ molecular sieves for $30 \mathrm{~min}$ at room temperature. Dibenzyl phosphate $(1.33 \mathrm{~g}, 4.79 \mathrm{mmol})$ and $\mathrm{Ag}_{2} \mathrm{CO}_{3}(0.88 \mathrm{~g}, 3.19$ mmol) were added and the solution was stirred for $7 \mathrm{~h}$ in the dark. The mixture was filtered and concentrated. Silica gel chromatography (1:1 hexane-EtOAc) yielded 10 (743 mg, 91\%) as a light yellow syrup $\left(R_{f} 0.37,1: 1\right.$ hexaneEtOAc). ${ }^{1} \mathrm{H}$ NMR analysis showed the $\beta$ anomer exclusively. ${ }^{1} \mathrm{H} \mathrm{NMR}\left(\mathrm{CDCl}_{3}, 400 \mathrm{MHz}\right) \delta 1.20\left(\mathrm{~d}, J_{6,5}=6.4\right.$, $3 \mathrm{H}, \mathrm{H}-6), 2.06$ (s, $\left.3 \mathrm{H}, \mathrm{C}(\mathrm{O}) \mathrm{CH}_{3}\right), 2.17$ (s, $\left.3 \mathrm{H}, \mathrm{C}(\mathrm{O}) \mathrm{CH}_{3}\right)$, $3.93\left(\mathrm{dq}, J_{5,4}=1.1\right.$ and $\left.J_{5,6}=6.4,1 \mathrm{H}, \mathrm{H}-5\right), 4.61\left(\mathrm{ddd}, J_{2,1}\right.$ $=7.7, J_{2,3}=9.9$, and $\left.J_{2,2 \mathrm{~F}}=51.7,1 \mathrm{H}, \mathrm{H}-2\right), 5.06-5.16$ $\left(\mathrm{m}, 5 \mathrm{H}, \mathrm{H}-3,2 \mathrm{CH}_{2} \mathrm{Ph}\right), 5.28\left(\mathrm{ddd}, J_{4,5}=1.1\right.$ and $J_{4,3} \approx J_{4, \mathrm{~F}}$ $\approx 3.2,1 \mathrm{H}, \mathrm{H}-4), 5.38\left(\mathrm{ddd}, J_{1, \mathrm{~F}}=3.9, J_{1, \mathrm{P}}=7.3\right.$, and $J_{1,2}$ $=7.7,1 \mathrm{H}, \mathrm{H}-1)$, and 7.30-7.38 (m, $\left.10 \mathrm{H}, 2 \mathrm{C}_{6} \mathrm{H}_{5}\right) ;{ }^{13} \mathrm{C}$ NMR $\left(\mathrm{CDCl}_{3}, 100 \mathrm{MHz}\right) \delta 15.7$ (C-6), 20.50, 20.54 (2 C(O)$\mathrm{CH}_{3}$ ), 69.48, 69.54, 69.6, 70.2, 70.3, 70.4 (C-4, C-5), 71.0 $\left(\mathrm{d}, J_{3, \mathrm{~F}}=18.5, \mathrm{C}-3\right), 87.8\left(\mathrm{dd}, J_{2, \mathrm{P}}=9.2\right.$ and $J_{2, \mathrm{~F}}=188.8$, C-2), $96.3\left(\mathrm{dd}, J_{1, \mathrm{P}}=4.7\right.$, and $\left.J_{1, \mathrm{~F}}=23.9, \mathrm{C}-1\right), 127.83$, $127.86,127.92,127.99,128.47,128.51,128.56,128.59(10$ C, aromatic), 135.27, 135.34, 135.38, 135.46 (2 d, 2 C, quartet aromatic), 169.8, and $170.2(2 \mathrm{C}=\mathrm{O}) ;{ }^{19} \mathrm{~F} \mathrm{NMR}$ $\left(\mathrm{CDCl}_{3}\right) \delta-171.2 ;{ }^{31} \mathrm{P} \mathrm{NMR}\left(\mathrm{CDCl}_{3}\right) \delta-2.19 ;$ HRMS calcd for $\mathrm{C}_{24} \mathrm{H}_{28} \mathrm{CsFO}_{9} \mathrm{P}\left(\mathrm{M}+\mathrm{Cs}^{+}\right)$643.0509, found 643.0539 .

(E) Di(cyclohexylammonium)-2-deoxy-2-fluoro- $\alpha$-l-fucopyranosyl Phosphate (11). The fully protected sugar phosphate 10 (692 $\mathrm{mg}, 1.36 \mathrm{mmol})$ was dissolved in a mixture of toluene $(8 \mathrm{~mL})$, pyridine $(1.5 \mathrm{~mL})$, and $\mathrm{Et}_{3} \mathrm{~N}(1.2 \mathrm{~mL})$. Palladium on carbon $(10 \%)(60 \mathrm{mg})$ was added and the solution was stirred under a hydrogen atmosphere for $14 \mathrm{~h}$. The mixture was filtered, evaporated, and coevaporated with toluene to yield bis(triethylammonium)-3,4-di- $O$-acetyl-2deoxy-2-fluoro- $\beta$-1-fucopyranosyl phosphate as a white foam (602 mg) $\left(R_{f} 0.57,2: 1 i-\mathrm{PrOH}_{-1} \mathrm{M} \mathrm{NH}_{4} \mathrm{OAc}\right) .{ }^{1} \mathrm{H} \mathrm{NMR}$ $\left(\mathrm{CDCl}_{3}, 400 \mathrm{MHz}\right) \delta 1.18\left(\mathrm{~d}, J_{6,5}=6.3,3 \mathrm{H}, \mathrm{H}-6\right), 2.05(\mathrm{~s}$, $\left.3 \mathrm{H}, \mathrm{C}(\mathrm{O}) \mathrm{CH}_{3}\right), 2.14$ (s, $\left.3 \mathrm{H}, \mathrm{C}(\mathrm{O}) \mathrm{CH}_{3}\right), 3.98$ (br. q, $J_{5,6}=$ 6.4, $1 \mathrm{H}, \mathrm{H}-5), 4.48\left(\mathrm{ddd}, J_{2,1}=7.8, J_{2,3}=9.7\right.$, and $J_{2, \mathrm{~F}}=$ $51.9,1 \mathrm{H}, \mathrm{H}-2), 5.14$ (ddd, $J_{3,4} \approx 3.5, J_{3,2} \approx 9.9$, and $J_{3, \mathrm{~F}} \approx$ $13.1,1 \mathrm{H}, \mathrm{H}-3), 5.24(\mathrm{~m}, 1 \mathrm{H}, \mathrm{H}-4)$, and 5.30 (ddd, $J_{1, \mathrm{~F}} \approx$ $3.5, J_{1,2} \approx 7.8$, and $\left.J_{1, \mathrm{P}} \approx 7.9,1 \mathrm{H}, \mathrm{H}-1\right) ;{ }^{13} \mathrm{C} \mathrm{NMR}\left(\mathrm{CDCl}_{3}\right.$, $100 \mathrm{MHz}) \delta 15.9(\mathrm{C}-6), 20.5,20.6\left(2 \mathrm{C}(\mathrm{O}) \mathrm{CH}_{3}\right), 69.2(\mathrm{C}-$ 5), $71.1\left(\mathrm{~d}, J_{4, \mathrm{~F}}=8.2, \mathrm{C}-4\right), 71.4\left(\mathrm{~d}, J_{3, \mathrm{~F}}=18.6, \mathrm{C}-3\right), 88.6$ $\left(\mathrm{dd}, J_{2, \mathrm{P}}=8.1\right.$ and $\left.J_{2, \mathrm{~F}}=185.8, \mathrm{C}-2\right), 95.4\left(\mathrm{dd}, J_{1, \mathrm{P}}=4.3\right.$ and $\left.J_{1, \mathrm{~F}}=22.8, \mathrm{C}-1\right), 169.9$ and $170.5(2 \mathrm{C}=\mathrm{O})$; HRMS calcd for $\mathrm{C}_{10} \mathrm{H}_{16} \mathrm{FNaO}_{9} \mathrm{P}\left(\mathrm{M}+\mathrm{Na}^{+}\right)$353.0414, found 353.0420 .

Crude bis(triethylammonium)-3,4-di- $O$-acetyl-2-deoxy-2fluoro- $\beta$-1-fucopyranosyl phosphate $(577 \mathrm{mg}$ ) was dissolved in $\mathrm{MeOH}(5 \mathrm{~mL})$, and cyclohexylamine $(5 \mathrm{~mL})$ was added, forming a precipitate. The mixture was heated to reflux for $1.5 \mathrm{~h}$, during which the solution clarified, and the product 
finally precipitated. After $4.5 \mathrm{~h}$, the mixture was cooled to room temperature, filtered, and the precipitate (a white solid) was washed three times with chloroform and dried (465 mg). The filtrate was evaporated to dryness, dissolved in water, washed three times with chloroform, and evaporated to yield a white solid. Recrystallization of filtrate residue from hot ethanol yielded an additional $87 \mathrm{mg}$, to give a total of 552 mg (95\% overall yield) of product 11. ${ }^{1} \mathrm{H}$ NMR $\left(\mathrm{D}_{2} \mathrm{O}, 400\right.$ $\mathrm{MHz}) \delta 1.15$ (m, $2 \mathrm{H}$, cha), 1.23 (d, $\left.J_{6,5}=6.5,3 \mathrm{H}, \mathrm{H}-6\right)$, 1.31 (m, $8 \mathrm{H}$, cha), 1.63 (m, $2 \mathrm{H}$, cha), 1.78 (m, $4 \mathrm{H}$, cha), 1.95 (m, $4 \mathrm{H}$, cha), 3.12 (m, $2 \mathrm{H}$, cha), 3.78 (m, $1 \mathrm{H}$, cha), 3.82 (br q, $\left.J_{5,6}=6.5,1 \mathrm{H}, \mathrm{H}-5\right), 3.93\left(\mathrm{ddd}, J_{3,4}=3.7, J_{3,2}\right.$ $=9.6$, and $\left.J_{3, \mathrm{~F}}=14.2,1 \mathrm{H}, \mathrm{H}-3\right), 4.27\left(\mathrm{ddd}, J_{2,1}=7.8, J_{2,3}\right.$ $=9.5$, and $\left.J_{2, \mathrm{~F}}=51.8,1 \mathrm{H}, \mathrm{H}-2\right)$, and $5.01\left(\mathrm{ddd}, J_{1, \mathrm{~F}}=3.5\right.$, $J_{1,2}=7.8$, and $\left.J_{1, \mathrm{P}}=8.4,1 \mathrm{H}, \mathrm{H}-1\right) ;{ }^{13} \mathrm{C} \mathrm{NMR}\left(\mathrm{D}_{2} \mathrm{O}, 100\right.$ MHz) $\delta 17.7$ (C-6), 26.2, 26.7, 32.8, 52.8 (cha), 73.5 (C-5), $73.9\left(\mathrm{~d}, J_{3, \mathrm{~F}}=17.4, \mathrm{C}-3\right), 74.4\left(\mathrm{~d}, J_{4, \mathrm{~F}}=8.8, \mathrm{C}-4\right), 94.4$ $\left(\mathrm{dd}, J_{2, \mathrm{P}}=6.8\right.$ and $\left.J_{2, \mathrm{~F}}=181.3, \mathrm{C}-2\right)$, and $97.3\left(\mathrm{dd}, J_{1, \mathrm{P}}=\right.$ 4.2 and $\left.J_{1, \mathrm{~F}}=23.2, \mathrm{C}-1\right)$; HRMS calcd for $\mathrm{C}_{6} \mathrm{H}_{12} \mathrm{FNaO}_{7} \mathrm{P}$ $\left(\mathrm{M}+\mathrm{Na}^{+}\right)$269.0202, found 269.0197.

Guanosine 5'-Diphospho-2-deoxy-2-fluoro- $\beta$-l-fucose, Monoammonium Salt (3). Compound 11 (100 mg, 235.5 $\mu \mathrm{mol})$ was dissolved in $\mathrm{H}_{2} \mathrm{O}(1 \mathrm{~mL})$, applied to a Bio-Rad AG 50W-X2 cation-exchange column $\left(\mathrm{Et}_{3} \mathrm{~N}^{+}, 1 \times 10 \mathrm{~cm}\right)$, and eluted with $\mathrm{H}_{2} \mathrm{O}(50 \mathrm{~mL})$. The solution was evaporated and coevaporated once with $\mathrm{MeOH}$ and three times with anhydrous pyridine $(1 \mathrm{~mL})$. To the dry residue was added guanosine $5^{\prime}$-monophospho morpholidate 4-morpholine- $N, N^{\prime}$ dicyclohexylcarboxamidine salt (223 mg, $282.6 \mu \mathrm{mol})$, and the two compounds were coevaporated three times with dry pyridine $(1.5 \mathrm{~mL})$, keeping the flask moisture-free by using argon to bring the pressure back to normal. $1 H$-Tetrazole (40 mg, $565.2 \mu \mathrm{mol}$ ) and dry pyridine $(1.1 \mathrm{~mL})$ were added, and the solution stirred for $27.5 \mathrm{~h}$ at room temperature. The mixture was then diluted with water $(1.5 \mathrm{~mL})$, evaporated, and coevaporated with water two times $(1.5 \mathrm{~mL})$. The residue was purified on a Bio-Gel P2 column $(2.5 \times 65 \mathrm{~cm})$, eluted with $250 \mathrm{mM} \mathrm{NH} \mathrm{HCO}_{3}$, to give 3 (106.1 mg, 74\%) as a white solid after lyophilization $\left(R_{f} 0.38,2: 1 i\right.$-PrOH-1 $\mathrm{M} \mathrm{NH} 4 \mathrm{OAc}) .{ }^{1} \mathrm{H} \mathrm{NMR}\left(\mathrm{CDCl}_{3}, 500 \mathrm{MHz}\right) \delta 1.19\left(\mathrm{~d}, J_{6,5}\right.$ $=6.5,3 \mathrm{H}$, H-6 Fuc), 3.75 (br dd, $J_{4,3} \approx J_{4, \mathrm{~F}} \approx 3.4,1 \mathrm{H}$, H-4 Fuc), 3.78 (br q, $J_{5,6}=6.5,1 \mathrm{H}, \mathrm{H}-5$ Fuc), 3.88 (ddd, $J_{3,4}=3.7, J_{3,2}=9.7$, and $J_{3, \mathrm{~F}}=14.3,1 \mathrm{H}, \mathrm{H}-3$ Fuc $), 4.19$ (m, 2 H, H-5 Rib), 4.32 (m, 1 H, H-4 Rib), 4.33 (ddd, $J_{2,1}=$ 7.6, $J_{2,3}=9.8$, and $\left.J_{2, \mathrm{~F}}=51.8,1 \mathrm{H}, \mathrm{H}-2 \mathrm{Fuc}\right), 4.49$ (dd, $J_{3,4}$ $=3.5$ and $\left.J_{3,2}=5.1,1 \mathrm{H}, \mathrm{H}-3 \mathrm{Rib}\right), 4.75\left(\mathrm{dd}, J_{2,3}=5.1\right.$ and $\left.J_{2,1}=6.0,1 \mathrm{H}, \mathrm{H}-2 \mathrm{Rib}\right), 5.14$ (ddd, $J_{1, \mathrm{~F}}=3.7, J_{1,2}=7.6$, and $\left.J_{1, \mathrm{P}}=8.0,1 \mathrm{H}, \mathrm{H}-1 \mathrm{Fuc}\right), 5.90\left(\mathrm{~d}, J_{1,2}=6.0,1 \mathrm{H}, \mathrm{H}-1\right.$ Rib), and 8.17 (s, $1 \mathrm{H}, \mathrm{H}-8$, base); ${ }^{13} \mathrm{C} \mathrm{NMR}\left(\mathrm{CDCl}_{3}, 125\right.$ MHz) $\delta 16.24$ (C-6 Fuc), 66.26 (d, $J=5.1$ ), 71.42, 72.28 $(\mathrm{d}, J=16.8), 72.73,72.78,74.74,84.91(\mathrm{~d}, J=8.8), 88.11$, $92.58\left(\mathrm{dd}, J_{\mathrm{C}, \mathrm{P}}=7.6\right.$ and $\left.J_{\mathrm{C}, \mathrm{F}}=181.9, \mathrm{C}-2^{\prime \prime}\right), 96.50(\mathrm{dd}$, $J_{\mathrm{C}, \mathrm{P}}=4.7$ and $\left.J_{\mathrm{C}, \mathrm{F}}=24.2, \mathrm{C}-1^{\prime \prime}\right), 116.52,138.54,152.66$, 155.10, and $159.63 ;{ }^{19} \mathrm{~F}$ NMR $\left(\mathrm{D}_{2} \mathrm{O}\right) \delta-171.3 ;{ }^{31} \mathrm{P}$ NMR $\left(\mathrm{D}_{2} \mathrm{O}\right) \delta-10.83\left(\mathrm{~d}, J_{\mathrm{P}, \mathrm{P}}=19.1\right)$ and $-12.66\left(\mathrm{~d}, J_{\mathrm{P}, \mathrm{P}}=19.1\right)$; HRMS calcd for $\mathrm{C}_{16} \mathrm{H}_{24} \mathrm{FN}_{5} \mathrm{O}_{14} \mathrm{P}_{2}\left(\mathrm{M}+\mathrm{H}^{+}\right)$592.0857, found 592.0870 .

Data Analysis. Precise kinetic constants for FucT V were determined with a nonlinear, least-squares fit of the kinetic data to the equation for an ordered sequential, bi-bi mechanism with the Sequenl FORTRAN program of Cleland (eq 1) (Cleland, 1979). Apparent kinetic parameters were determined by subjecting the data to nonlinear least-squares fit of the Michaelis-Menten equation with the Hypero FORTRAN program of Cleland (eq 2) (Cleland, 1979). The precise inhibitor constant for competitive inhibition was determined with the Compo FORTRAN program of Cleland (eq 3) (Cleland, 1979). Asterisks indicate apparent kinetic constants.

$$
\begin{gathered}
v=\left(V_{\mathrm{max}}[\text { LacNAc }][\mathrm{GDP}-\mathrm{fuc}]\right) / \\
\left(K_{\mathrm{i}, \mathrm{GDP}-\mathrm{fuc}} K_{\mathrm{m}, \mathrm{LacNAc}} / K_{\mathrm{m}, \mathrm{GDP}-\text { fuc }}+[\mathrm{GDP}-\mathrm{fuc}] K_{\mathrm{m}, \mathrm{LacNAc}}+\right. \\
\left.[\mathrm{LacNAc}] / K_{\mathrm{m}, \mathrm{GDP}-\text { fuc }}+[\mathrm{LacNAc}][\mathrm{GDP}-\mathrm{fuc}]\right) \\
v=V_{\max } *[\mathrm{~S}] /\left([\mathrm{S}]+K_{\mathrm{m}} *\right) \\
v=V_{\max } *[\mathrm{~S}] /\left\{[\mathrm{S}]+K_{\mathrm{m}} *\left(1+[\mathrm{I}] / K_{\mathrm{i}}\right)\right\}
\end{gathered}
$$

Fluorometric Assay for $\alpha-1,3-F u c o s y l t r a n s f e r a s e ~ V$ Activity. The fluorometric assay monitored GDP production using the pyruvate kinase/lactate dehydrogenase coupled enzymatic assay for the consumption of NADH based on an assay for GTPase activity (Gonzalo et al., 1995). NADH fluorescence has an excitation wavelength of $340 \mathrm{~nm}$ and an emission wavelength of $460 \mathrm{~nm}$. All solutions were filtered through a $0.22-\mu \mathrm{m}$ filter. A $0.460-\mathrm{mL} 100 \mathrm{mM} \operatorname{MES}(\mathrm{pH} 7.7)$ coupling enzyme buffer contained the coupling substrates and cofactors $(0.032 \mathrm{mM} \mathrm{NADH}, 0.50 \mathrm{mM}$ PEP, $2 \mathrm{mM}$ $\mathrm{MnCl}_{2}$ ). The assay reactions were individually incubated in the fluorometer at $37^{\circ} \mathrm{C}$ until a flat baseline was achieved. The coupled enzymatic reactions were initiated with the addition of $0.040 \mathrm{~mL}$ of a coupling enzyme solution that contained 69 units of rabbit muscle pyruvate kinase and 27 units of rabbit muscle lactate dehydrogenase. A standard curve of the change in absorbance at $460 \mathrm{~nm}$ was prepared with $0.5,1.0,2.0,4.0$, and $8.0 \mu \mathrm{M}$ GDP and had the following for typical results: $0.64,1.42,2.57,4.40$, and 8.69. A value of 1.3 absorbance units was observed per $1.0 \mu \mathrm{M}$ of GDP. These results correlated with the change in emission at $460 \mathrm{~nm}$ predicted by multiplying the ratio of the GDP and NADH concentrations to the total initial fluorescence at $460 \mathrm{~nm}$.

A time course of the fucosyltransferase reaction was determined. A 0.700-mL reaction containing $0.05 \mathrm{mM}$ GDPFuc, $0.60 \mathrm{mM}$ LacNAc- $\beta$-O- $\left(\mathrm{CH}_{2}\right)_{5} \mathrm{CO}_{2} \mathrm{CH}_{3}, 10 \mathrm{mM} \mathrm{MnCl}$, and 75.6 milliunits of FucT V. At the following time points, 0.100-mL aliquots were taken: 5, 10, 30, 45, 90, and 130 min. The reactions were quenched with the addition of 0.460 $\mathrm{mL}$ of coupled enzymatic assay buffer (100 mM MES, $\mathrm{pH}$ 7.7) that contained the required amounts of PEP, NADH, and $\mathrm{MnCl}_{2}$. After equilibration of the sample at $37{ }^{\circ} \mathrm{C}$, a 0.040-mL solution of pyruvate kinase and lactate dehydrogenase was added. The change in emission at $460 \mathrm{~nm}$ that occurred in $20 \mathrm{~s}$ was measured. The time course was linear to the $45 \mathrm{~min}$. Initial rate data were subsequently taken after $30 \mathrm{~min}$ of reaction.

Secondary Isotope Effect on the FucT V Reaction. GDPFuc and GDP- $\left[1-{ }^{2} \mathrm{H}\right] \mathrm{Fuc}$ were synthesized and characterized in an identical manner. Each $0.1 \mathrm{mM}$ assay reaction contained 10.8 milliunit of FucT V, 0.6 mM LacNAc- $\beta$-O$\left(\mathrm{CH}_{2}\right)_{5} \mathrm{CO}_{2} \mathrm{CH}_{3}$, and $10 \mathrm{mM} \mathrm{MnCl}$ in a $20 \mathrm{mM} \mathrm{MES}$ buffer (pH 6.0). Reactions were $30 \mathrm{~min}$ at room temperature. GDPFuc and GDP-[1-2 $\mathrm{H}]$ Fuc were both varied $(6.25,12.5,25$, $50,100$, and $200 \mu \mathrm{M})$. The fucosyltransferase reactions were terminated with the addition of $0.460 \mathrm{~mL}$ of $100 \mathrm{mM}$ MES 
Scheme 1
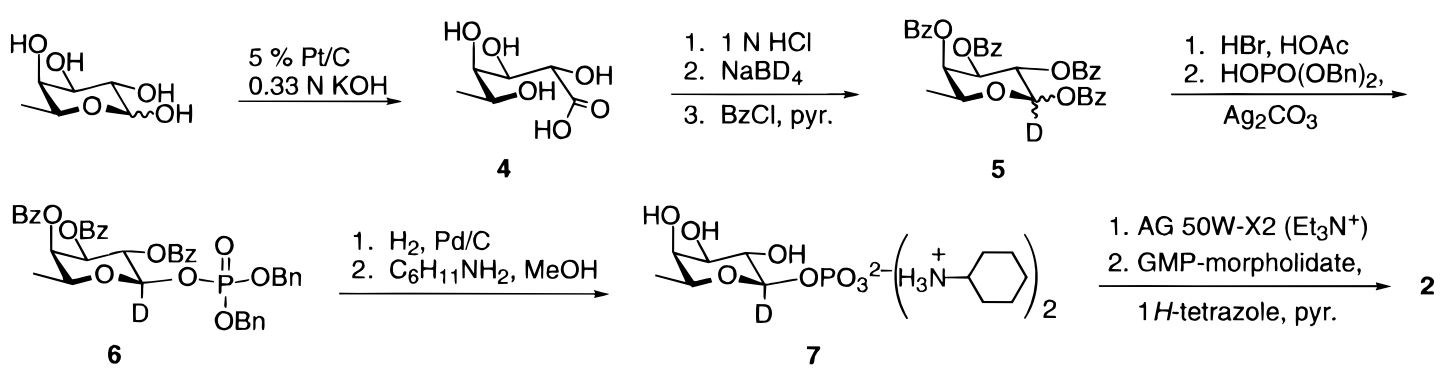

Scheme 2

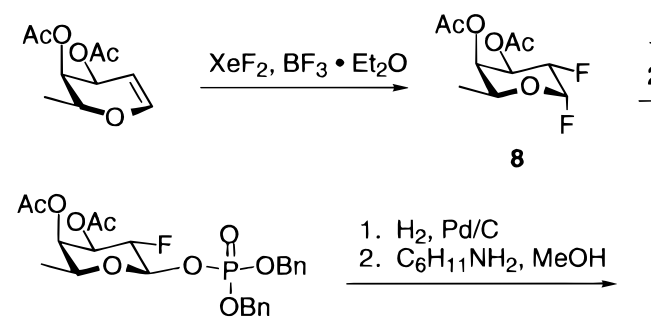

10
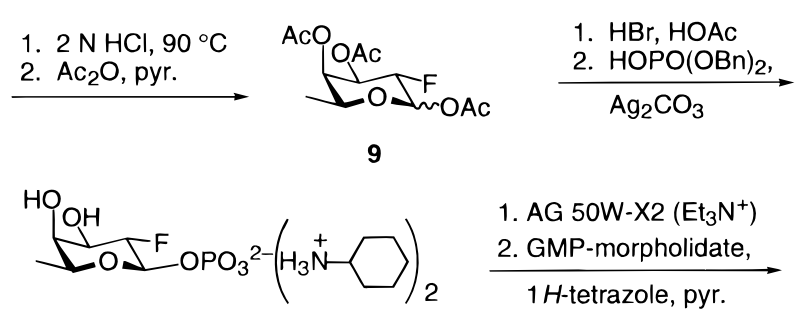

1. $A G 50 W-X 2\left(\mathrm{Et}_{3} \mathrm{~N}^{+}\right)$

$\underset{\text { 2. GMP-tetrazole, pyr. }}{\stackrel{\text { 1Horpholidate, }}{\longrightarrow}} 3$

11
(pH 7.7) buffer that contained the coupling substrates and cofactors (0.032 mM NADH, $0.50 \mathrm{mM}$ PEP, and $2 \mathrm{mM}$ $\mathrm{MnCl}_{2}$ ). The assay reactions were individually incubated in the fluorometer at $37^{\circ} \mathrm{C}$ until a flat baseline was achieved. The coupled enzymatic reactions were initiated with the addition of $0.040 \mathrm{~mL}$ of a coupling enzyme solution (69 units of rabbit muscle pyruvate kinase and 27 units of rabbit muscle lactate dehydrogenase). From the calibration curve, the change in emission at $460 \mathrm{~nm}$ of 1 unit is equal to 462 pmol of GDP produced in the 30-min reaction and thus is $15.4 \mathrm{pmol} / \mathrm{min}$. The background, nonenzymatic contribution of the GDP-Fuc solution was accounted for by determining the change in emission at $460 \mathrm{~nm}$ as a function of GDP-Fuc concentration. The observed isotope effects were corrected for protio contamination in deuterated GDP- $\left[1-{ }^{2} \mathrm{H}\right] \mathrm{Fuc}$ as described in the literature (Caldwell et al., 1991; Hengge \& Hess, 1994).

Radiolabel $\alpha-1,3-F u c o s y l t r a n s f e r a s e ~ V$ Activity Assay. The activity of FucT $\mathrm{V}$ was detected by the GDP-[U- $\left.{ }^{14} \mathrm{C}\right]-$ fucose assay described previously in which GDP-[U- $\left.{ }^{14} \mathrm{C}\right]-$ fucose is separated from $\left[\mathrm{U}^{14} \mathrm{C}\right]$ fucosylated product by anion-exchange chromatography(Murray et al., 1996). Typically, assays contained $10 \mathrm{mM} \mathrm{MnCl} 2,0.3$ milliunit of purified FucT V, and $25 \mathrm{mM}$ cacodylate buffer ( $\mathrm{pH}$ 6.2) in a total assay volume of $0.05 \mathrm{~mL}$. Assays were performed at $25{ }^{\circ} \mathrm{C}$. Reactions were halted with the addition of 0.5 $\mathrm{mL}$ of distilled, deionized water. GDP-Fuc was separated from the product, Lewis $\mathrm{x}$, with a $1.0-\mathrm{mL}$ Dowex 1-X8 pipette column. The reaction mixtures were applied to the column and washed with $0.3 \mathrm{~mL}$ of distilled, deionized water three times. The flowthrough and the column washes were collected in $10 \mathrm{~mL}$ of ScintiVerse I scintillation cocktail. Control reactions, without enzyme, were used to establish the background, nonenzymatic cleavage rate. A typical control reaction of $32672 \mathrm{cpm}$ of guanosine $5^{\prime}$-diphospho1 -[U- $\left.{ }^{14} \mathrm{C}\right]$ fucose would result in $173 \mathrm{cpm}$ of nonenzymatic column flowthrough.

Inhibition of FucT by GDP-2F-Fuc. GDP-Fuc concentration was varied $(10,25,50$, and $100 \mu \mathrm{M})$ at fixed concentrations of GDP-2F-Fuc $(0,20,40$, and $80 \mu \mathrm{M})$, and the acceptor sugar, LacNAc- $\beta$-O- $\left(\mathrm{CH}_{2}\right)_{5} \mathrm{CO}_{2} \mathrm{CH}_{3}$, was kept at twice its $K_{\mathrm{m}}$ level, $0.6 \mathrm{mM}$. Each assay contained 0.3 milliunit of FucT V and $10 \mathrm{mM} \mathrm{MnCl}_{2}$ in a $100 \mathrm{mM} \mathrm{MES}$ buffer (pH 6.0). Reactions were $30 \mathrm{~min}$ at room temperature. The precise $K_{\mathrm{i}}$ was determined with a nonlinear, least-squares fit of the data to the equation for competitive inhibition (eq 3).

Evidence that GDP-2F-Fuc was not a slow substrate or an inactivator was obtained. A $0.350-\mathrm{mL}$ solution contained $10 \mathrm{mM} \mathrm{MnCl2}, 2.1$ milliunits of FucT V, $0.30 \mathrm{mM}$ LacNAc$\beta$-O- $\left(\mathrm{CH}_{2}\right)_{5} \mathrm{CO}_{2} \mathrm{CH}_{3}, 0.010 \mathrm{mM}$ GDP-2F-Fuc, and $100 \mathrm{mM}$ MES ( $\mathrm{pH}$ 6.0). This solution was subject to incubation at room temperature for various time periods $(0,3,10,20,30$, 60 , and $80 \mathrm{~min})$. After the incubation time, a $0.050-\mathrm{mL}$ aliquot was removed and GDP-[U- $\left.{ }^{14} \mathrm{C}\right]$ fucose was added to a final concentration of $0.050 \mathrm{mM}$ to initiate the fucosyltransfer reaction. After a 30-min reaction time period, the solution was passed through a Dowex 1 column and the amount of product was determined. A control reaction was performed that did not contain GDP-2F-Fuc; this was used in the calculation of percent inhibition.

\section{RESULTS AND DISCUSSION}

GDP-Fuc, GDP-[1-2 H]Fuc, and GDP-2F-Fuc were synthesized from the corresponding fucosyl phosphate derivatives using an improved procedure for the coupling with GMP-morpholidate. $\beta$-1-Fucopyranosyl phosphate was conveniently prepared by literature procedures (Adelhorst \& Whitesides, 1993; Ichikawa et al., 1992b) For the synthesis of the 1-deuterio derivative 7 (Scheme 1), 1-fucose was converted to 1-fuconic acid $\mathbf{4}$ by catalytic dehydrogenation with platinum on carbon in basic solution (de Wit et al., 1978). After acid-catalyzed dehydration, the intermediately formed fuconolactone was reduced with sodium borodeuteride (Wolfrom \& Wood, 1951) to give $\left[1-^{2} \mathrm{H}\right]$ fucose. The ongoing steps were the same as for the protio compound and are summarized in Scheme 1. For the synthesis of 2-deoxy-2-fluoro- $\beta$-1-fucosyl phosphate 11 (Scheme 2), 3,4di- $O$-acetyl-1-fucal was converted to the acetylated 1,2 difluoro compound $\mathbf{8}$ using xenon difluoride (Korytnyk, 1982). Hydrolysis of $\mathbf{8}$ with hydrochloric acid and acety- 

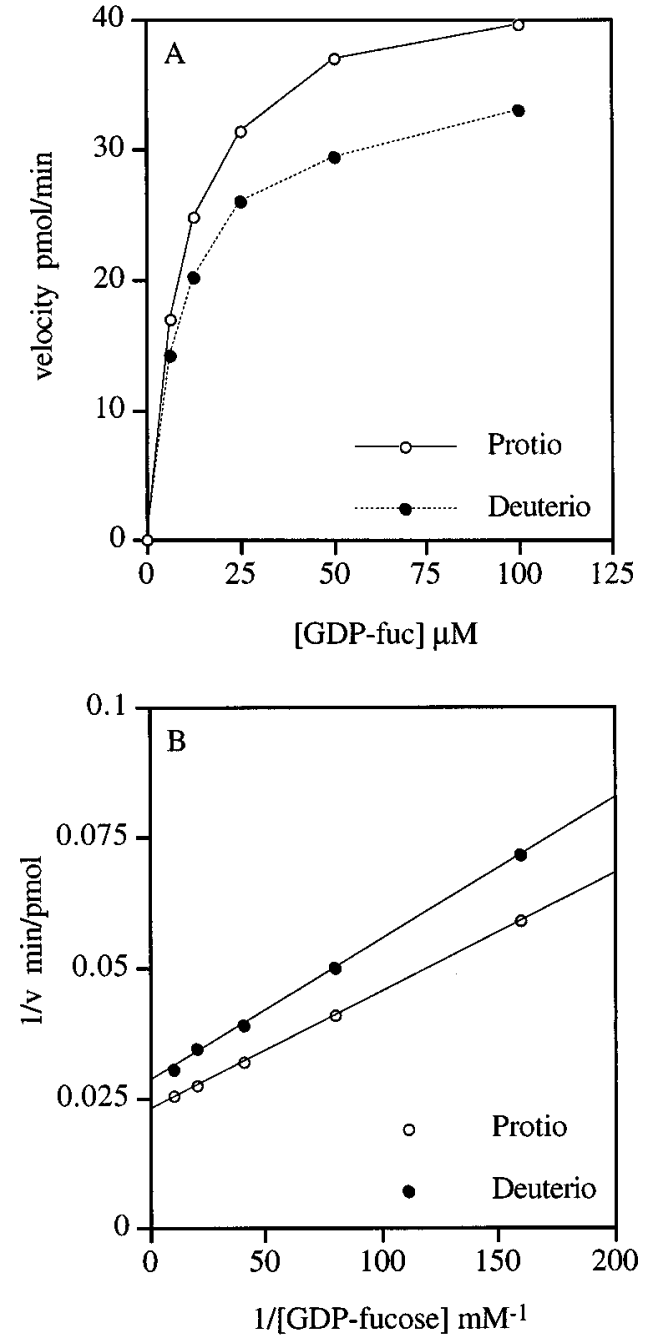

FIGURE 3: Secondary isotope effect on the $\alpha$-1,3-fucosyltransferase $\mathrm{V}$ reaction from GDP-[1-2 $\mathrm{H}]-$ Fuc. The secondary isotope effect was determined to be $\mathrm{D}_{V}=1.26 \pm 0.13$ and $\mathrm{D}_{V / K}=1.22 \pm 0.07$ was determined by a nonlinear fit of the data to the Michaelis-Menten equation (eq 2). GDP-[1-2 H]-Fuc and GDP-Fuc were varied from 6.25 to $100 \mu \mathrm{M}$ at a constant concentration of LacNAc- $\beta$-O- $\left(\mathrm{CH}_{2}\right)_{5^{-}}$ $\mathrm{CO}_{2} \mathrm{CH}_{3}$ of $0.30 \mathrm{mM}$. The secondary isotope was expressed as a function of velocity and GDP-Fuc concentration (A) and in a double-reciprocal format (B).

lation gave the 2-fluoro-1-fucose derivative 9. Treatment with hydrobromic acid followed by phosphorylation with dibenzyl phosphate and silver carbonate in methylene chloride-ether-acetonitrile gave the $\beta$-1-fucosyl phosphate 10. The benzyl groups were removed hydrogenolytically, and deacetylation with cyclohexylamine in methanol gave crystalline deprotected 2-deoxy-2-fluoro- $\beta$-1-fucopyranosyl phosphate $\mathbf{1 1}$ as its di(cyclohexylammonium) salt. Before the coupling with GMP-morpholidate, all fucosyl phosphates were converted into their triethylammonium salts by passage through a cation-exchange column $\left(\mathrm{Et}_{3} \mathrm{~N}^{+}\right.$form) in order to get material soluble under the conditions of the coupling reaction.

The reaction of fucosyl phosphate and GMP-morpholidate is usually carried out in pyridine, but even after a reaction time of 5 days we were able to detect large amounts of both starting materials, as judged by TLC. As the morpholino group has to become protonated to serve as an efficient leaving group, we felt that the addition of an acid catalyst probably could enhance the outcome of the reaction. $1 \mathrm{H}$ Tetrazole $\left(\mathrm{p} K_{\mathrm{a}} 4.9\right)$ is commonly used for the activation of

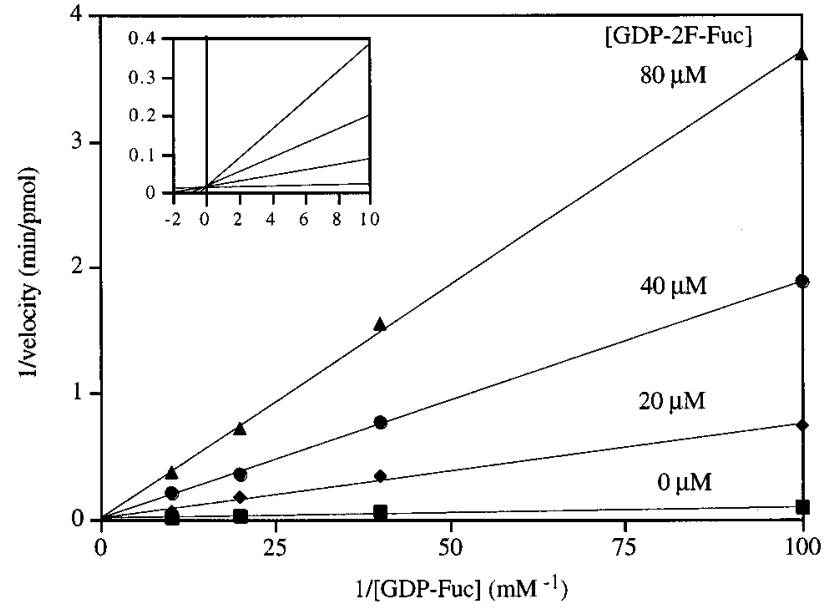

Figure 4: GDP-2F-Fuc is shown to be a potent competitive inhibitor with a $K_{\mathrm{i}}=4.2 \pm 0.6 \mu \mathrm{M}$. GDP-Fuc concentration was varied $(10,25,50$, and $100 \mu \mathrm{M})$ and the acceptor sugar, LacNAc$\beta$-O- $\left(\mathrm{CH}_{2}\right)_{5} \mathrm{CO}_{2} \mathrm{CH}_{3}$, was kept at twice its $K_{\mathrm{m}}$ level, $0.6 \mathrm{mM}$. (Inset) Expansion of the $y$-axis intercept. Within the experimental error a common intercept is observed, consistent with a competitive mode of inhibition. The precise $K_{\mathrm{i}}$ was determined with a nonlinear, leastsquares fit of the data to the equation for competitive inhibition (eq 3).

phosphoramidites (Sim, 1993) and it turned out that this heterocycle is also an efficient catalyst for the phosphoramidate coupling. Depending on the equivalents of fucosyl phosphate and GMP-morpholidate used, the reaction is complete after 1 or 2 days. A detailed study on the mechanism of this catalysis is in due course and will be published elsewhere. In this way, GDP-Fuc, GDP- $\left[1-{ }^{2} \mathrm{H}\right]-$ Fuc, and GDP-2F-Fuc were obtained as their monoammonium salts in yields of $85 \%, 78 \%$, and $74 \%$, respectively.

A fluorescence-based assay was developed in order to determine the secondary isotope effect on $\alpha-1,3$-fucosyltransferase $\mathrm{V}$ processing of GDP-[1-2 $\mathrm{H}]$ Fuc. This assay coupled the production of GDP to the consumption of NADH with pyruvate kinase and lactate dehydrogenase and was derived from the fluorescence assay developed for GTPases (Gonzalo et al., 1995). NADH has an excitation wavelength of $340 \mathrm{~nm}$ and an emission wavelength of $460 \mathrm{~nm}$. A standard curve of the change in absorbance at $460 \mathrm{~nm}$ was prepared with $0.5,1.0,2.0,4.0$, and $8.0 \mu \mathrm{M}$ GDP and had the following for typical results: $0.64,1.42,2.57,4.40$, and 8.69. A value of 1.3 absorbance units was observed per 1.0 $\mu \mathrm{M}$ of GDP. From the calibration curve, the change in emission at $460 \mathrm{~nm}$ of 1 emission unit is equal to $462 \mathrm{pmol}$ of GDP produced in the 30-min reaction and thus is 15.4 $\mathrm{pmol} / \mathrm{min}$. A time course of the fucosyltransferase reaction was determined to be linear to $45 \mathrm{~min}$, and initial rate data were subsequently taken after $30 \mathrm{~min}$ of reaction.

A secondary isotope effect on the $\alpha-1,3$-fucosyltransferase $\mathrm{V}$ reaction from GDP- $\left[1-{ }^{2} \mathrm{H}\right]$ Fuc was determined to be $\mathrm{D}_{V}$ $=1.32 \pm 0.13$ and $\mathrm{D}_{V / K}=1.27 \pm 0.07$ using the fluorescence assay (Figure 3). Precise kinetic data were derived from a nonlinear, least-squares fit of the data to eq 2 . The possibility of trivial fluorescence quenching (absorbance at either 340 or $460 \mathrm{~nm}$ ) was eliminated by testing each component of the assay solution. The assay solutions for both GDP-Fuc and GDP- $\left[1-{ }^{2} \mathrm{H}\right]$ Fuc were prepared from a common stock solution such that the only variable was GDP-Fuc. Protio and deuterio GDP-fucose solutions were subjected to the coupled assay solution in the absence of FucT V to eliminate 


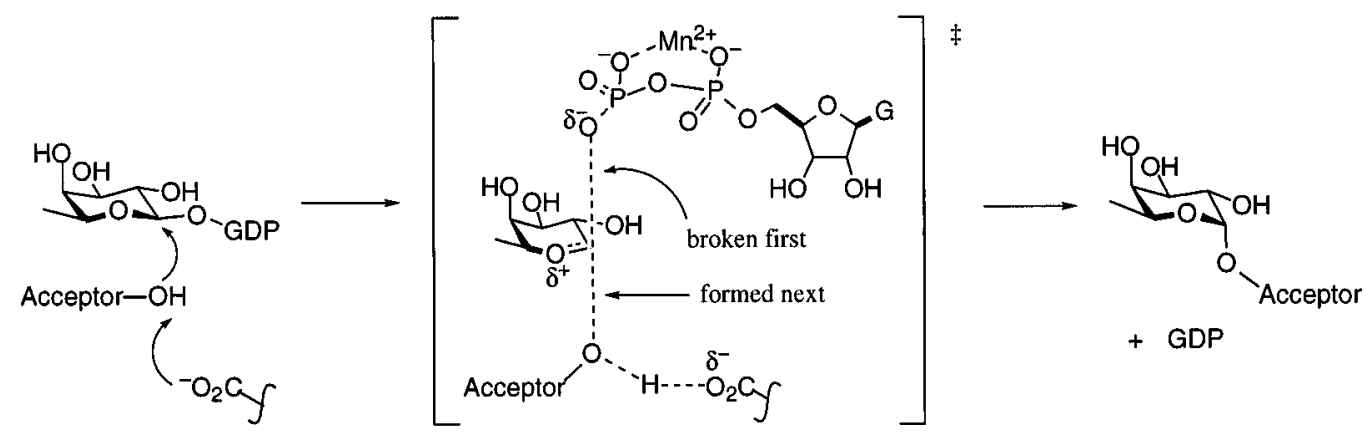

FIGURE 5: Proposed mechanism for human $\alpha-1,3$-fucosyltransferase $V$ reaction. Both the observation of a secondary isotope effect of GDP- $\left[1-{ }^{2} \mathrm{H}\right]-$ Fuc and the inhibition of GDP-2F-Fuc are consistent with significant glycosidic bond cleavage prior to the nucleophile attack on the anomeric position of GDP-Fuc. The proton inventory study suggests one-proton transfer in the transition state.

the possibility that the change in emission at $460 \mathrm{~nm}$ was due to either a GDP contamination or a compound that absorbs at either 340 or $460 \mathrm{~nm}$. The observed isotope effects were corrected for protio contamination in deuterated GDP- $\left[1-{ }^{2} \mathrm{H}\right] \mathrm{Fuc}$ as described in the literature (Caldwell et al., 1991, Hengge \& Hess, 1994). $\beta$-1,4-Galactosyltransferase has been shown to have a secondary isotope effect $\left(\mathrm{D}_{V}=1.21, \mathrm{D}_{V / K}=1.05\right)$ (Kim et al., 1988) Studies of glycosidases have used the $\alpha$-hydrogen isotope effect to show $\mathrm{sp}^{2}$ hybidization in the reaction center (Dahlquist et al., 1969; Kempton \& Withers, 1992; Rosenberg \& Kirsch, 1981; Smith et al., 1973).

The interaction of GDP-2F-Fuc with FucT V was evaluated. The mode of inhibition of FucT $V$ by GDP-2F-Fuc was evaluated by varying the GDP-Fuc concentrations at fixed GDP-2F-Fuc concentrations at a constant LacNAc- $\beta$ $\mathrm{O}-\left(\mathrm{CH}_{2}\right)_{5} \mathrm{CO}_{2} \mathrm{CH}_{3}$ concentration. The double-reciprocal plot showed a competitive inhibition pattern (Figure 4). An inhibition constant for GDP-2F-Fuc was determined to be $4.2 \pm 0.6 \mu \mathrm{M}$ by a nonlinear least-squares fit of the data to the equation for competitive inhibition (eq 3). Evidence that GDP-2F-Fuc was not a slow substrate or an inactivator was obtained. Preincubation of $0.010 \mathrm{mM}$ GDP-2F-Fuc with the FucT $\mathrm{V}$ in the presence of LacNAc- $\beta-\mathrm{O}-\left(\mathrm{CH}_{2}\right)_{5} \mathrm{CO}_{2} \mathrm{CH}_{3}$ and $\mathrm{MnCl}_{2}$ was performed for $0-80 \mathrm{~min}$. The reactions were initiated with GDP-Fuc and allowed to react for $30 \mathrm{~min}$. The percent inhibition remained constant at $58 \%$, which is expected for reversible inhibition. If GDP-2F-Fuc was either an inactivator or a slow substrate, then the inhibition would either increase or decrease as a function of time. This result is different from the results for the hydrolysis of 2-fluoroglycosides by retaining glycosidases which form a covalent adduct in the active site, a mechanism-based inactivation (McCarter et al., 1993; Withers et al., 1988).

In summary, the results of isotope effect and inhibition study suggest that the glycosidic cleavage occurs prior to the nucleophilic attack, a process between $\mathrm{SN}_{1}$ and $\mathrm{SN}_{2}$ reactions (Figure 5).

\section{REFERENCES}

Adelhorst, K., \& Whitesides, G. M. (1993) Carbohydr. Res. 242, 69-76.

Arlt, M., \& Hindsgaul, O. (1995) J. Org. Chem. 60, 14-15.

Caldwell, S. R., Raushel, F. M., Weiss, P. M., \& Cleland, W. W. (1991) Biochemistry 30, 7444-7450.

Cleland, W. W. (1979) Methods Enzymol. 63, 103-138.

Dahlquist, F. W., Rand-Meir, T., \& Raftery, M. A. (1969) Biochemistry 8, 4214-4221. de Wit, G., de Vlieger, J. J., Kock-van Dalen, A. C., Kieboom, A. P. G., \& van Bekkum, H. (1978) Tetrahedron Lett. 15, 13271330.

Foxall, C., Watson, S. R., Dowbenko, D., Fennie, C., Lasky, L. A., Kiso, M., Itasagawa, A., Asa, D., \& Brandley, B. K. (1992) J. Cell Biol. 117, 895-902.

Gokhale, U. B., Hindsgaul, O., \& Palcic, M. M. (1990) Can. J. Chem. 68, 1063-1071.

Gonzalo, P., Sontag, B., Guillot, D., \& Reboud, J.-P. (1995) Anal. Biochem. 225, 178-180.

Hayashi, T., Murray, B. W., Wang, R., \& Wong, C.-H. (1996) Angew. Chem. (submitted for publication).

Hengge, A. C., \& Hess, R. A. (1994) J. Am. Chem. Soc, 116, $11256-11263$.

Ichikawa, Y., Lin, Y.-C., Dumas, D. P., Shen, G.-J., Garcia-Junceda, E., Williams, M. A., Bayer, R., Ketcham, C., Walker, L. E., Paulson, J. C., \& Wong, C.-H. (1992a) J. Am. Chem. Soc. 114, 9283-9298.

Ichikawa, Y., Sim, M. M., \& Wong, C.-H. (1992b) J. Org. Chem. 57, 2943-2946.

Ichikawa, Y., Halcomb, R. L., \& Wong, C.-H. (1994) Chem. Br., 117-121.

Kempton, J. B., \& Withers, S. G. (1992) Biochemistry 31, 99619969.

Kim, S. C., Singh, A. N., \& Raushel, F. M. (1988) Arch. Biochem. Biophys. 267, 54-59.

Korytnyk, W., Valentekovic-Horvath, S., \& Petrie, C. R., III (1982) Tetrahedron 38, 2547-2550.

Kukowska-Latallo, J. F., Larsen, R. D., Nair, R. P., \& Lowe, J. B. (1990) Genes Dev. 4, 1288.

Lasky, L. A. (1992) Science 258, 964-969.

Look, G. C., Fotsch, C. H., \& Wong, C.-H. (1993) Acc. Chem. Res. 26, 182-190.

Lowe, J. B., Kukowska-Latallo, J. F., Nair, R. P., Larsen, R. D., Marks, R. M., Bacher, B. A., Kelly, R. J., \& Ernst, L. K. (1991) J. Biol. Chem. 266, 17467.

McCarter, J. D., \& Withers, S. G. (1996) J. Am. Chem. Soc. 118, 241-242.

McCarter, J. C., Adam, M., Braun, C., Namchuk, M., Tull, D., \& Withers, S. G. (1993) Carbohydr. Res. 249, 77.

McCurley, R. S., III, Olsen, A. S., Gingrich, J. C., Szczepaniak, D., Cameron, J. S., Krauss, R., \& Weston, B. W. (1995) Genomics 26, 142.

Moffatt, J. G. (1966) Methods Enzymol. 8, 136-142.

Muramatsu, T. (1993) Glycobiology 3, 294-296.

Murray, B. W., Takayama, S., Schultz, J., \& Wong, C.-H. (1996) Biochemistry 35, 11183-11195.

Nunez, H. A., O'Connor, J. V., Rosevear, P. R., \& Barker, R. (1981) Can. J. Chem. 59, 2086-2095.

Parekh, R. B., \& Edge, C. J. (1994) Trends Biotechnol. 12, 339345.

Porter, D. J. T., Merrill, B. M., \& Short, S. A. (1995) J. Biol. Chem. $270,15551$.

Qiao, L., Murray, B. W., Shimazaki, M., Schultz, J., \& Wong, C.H. (1996) J. Am. Chem. Soc. 118, 7653-7662.

Reguigne-Arnould, I., Coullin, P., Mollicone, R., Faure, S., Fletcher, A., Kelly, R. J., Lowe, J. B., \& Oriol, R. (1995) Cytogenet. Cell Genet. 71, 158-162. 
Roseman, S., Distler, J. J., Moffatt, J. G., \& Khorana, H. G. (1961) J. Am. Chem. Soc. 83, 659-663.

Rosenberg, S., \& Kirsch, J. F. (1981) Biochemistry 20, 3196-3204.

Sasaki, K., Jurata, K., Funayama, K., Nagata, M., Watanabe, E., Ohta, S., Hanai, N., \& Nishi, T. (1994) J. Biol. Chem. 269, 14730.

Sim, M. M., Kondo, H., \& Wong, C.-H. (1993) J. Am. Chem. Soc. $115,2260-2267$.

Sinnott, M. L. (1990) Chem. Rev. 90, 1171-1202.

Smith, L. E. H., Mohr, L. H., \& Raftery, M. A. (1973) J. Am. Chem. Soc. 95, 7497-7501.

Veeneman, G. H., Broxterman, H. J. G., van der Marel, G. A., \& van Boom, J. H. (1991) Tetrahedron Lett. 32, 6175-6178.

Weston, B. W., Nair, R. R., Larsen, R. D., \& Lowe, J. B. (1992a)
J. Biol. Chem. 267, 4152-4160.

Weston, B. W., Smith, P. L., Kelly, R. J., \& Lowe, J. B. (1992b) J. Biol. Chem. 267, 24575.

White, A., Tull, D., Johns, K., Withers, S. G., \& Rose, D. R. (1996) Nature Struct. Biol. 3, 149-154.

Withers, S. G., \& Street, I. P. (1988) J. Am. Chem. Soc. 110, 8551.

Withers, S. G., Rupitz, K., \& Street, I. P. (1988) J. Biol. Chem. $263,7929$.

Withers, S. G., Warren, R. A., Street, I. P., Rupitz, K., Kempton, J. B., \& Abersold, R. J. (1990) J. Am. Chem. Soc. 112, 5887.

Wolfrom, M. L., \& Wood, H. B. (1951) J. Am. Chem. Soc. 73, 2933-2934.

BI962284Z 